OPEN ACCESS

Edited by:

Trine N. Jorgensen,

Case Western Reserve University,

United States

Reviewed by:

Åsa Andersson,

Halmstad University, Sweden Abdurrahman Tufan,

Gazi University, Turkey

*Correspondence:

Chao Liang

liangc@sustech.edu.cn

${ }^{\dagger}$ These authors have contributed equally to this work

Specialty section: This article was submitted to Autoimmune and

Autoinflammatory Disorders,

a section of the journal

Frontiers in Immunology

Received: 26 March 2021 Accepted: 23 June 2021 Published: 09 July 2021

Citation:

Huang J, Fu X, Chen X, Li Z, Huang Y and Liang $C$ (2021) Promising

Therapeutic Targets for Treatment

of Rheumatoid Arthritis.

Front. Immunol. 12:686155. doi: 10.3389/fimmu.2021.686155

\section{Promising Therapeutic Targets for Treatment of Rheumatoid Arthritis}

\author{
Jie Huang ${ }^{1 \dagger}$, Xuekun $\mathrm{Fu}^{1 \dagger}$, Xinxin Chen ${ }^{1}$, Zheng $\mathrm{Li}^{1}$, Yuhong Huang ${ }^{1}$ and Chao Liang ${ }^{1,2 *}$ \\ ${ }^{1}$ Department of Biology, Southern University of Science and Technology, Shenzhen, China, 2 Institute of Integrated \\ Bioinfomedicine and Translational Science (IBTS), School of Chinese Medicine, Hong Kong Baptist University, \\ Hong Kong, China
}

Rheumatoid arthritis (RA) is a systemic poly-articular chronic autoimmune joint disease that mainly damages the hands and feet, which affects $0.5 \%$ to $1.0 \%$ of the population worldwide. With the sustained development of disease-modifying antirheumatic drugs (DMARDs), significant success has been achieved for preventing and relieving disease activity in RA patients. Unfortunately, some patients still show limited response to DMARDs, which puts forward new requirements for special targets and novel therapies. Understanding the pathogenetic roles of the various molecules in RA could facilitate discovery of potential therapeutic targets and approaches. In this review, both existing and emerging targets, including the proteins, small molecular metabolites, and epigenetic regulators related to RA, are discussed, with a focus on the mechanisms that result in inflammation and the development of new drugs for blocking the various modulators in RA.

Keywords: rheumatoid arthritis, targets, proteins, small molecular metabolites, epigenetic regulators

\section{INTRODUCTION}

Rheumatoid arthritis (RA) is classified as a systemic poly-articular chronic autoimmune joint disease that primarily affects hands and feet. RA is pathologically manifested as immune cell infiltration, hyperplasia of the synovial lining, pannus formation, and destruction of articular cartilage and bone $(1,2)$. Although the exact etiology of RA is unclear, it is certain that genetic and environmental factors have influences on RA occurrence. At present, RA affects approximately $0.5 \%$ to $1.0 \%$ of the population worldwide (3), and in particular, females are at higher risk of the disease (two to three times than males) (4). RA patients typically experience morning stiffness. If left untreated, they could appear small focal necrosis, adhesion of granulation, and fibrous tissue on the articular surface, which lead to progressive joint ankylosis, destruction, deformities, and disability (5).

To date, a large number of clinical trials have been performed by scientists and clinicians for testing different types of agents in RA treatment. Some of these agents have been approved for daily clinical practice. In the first place, nonsteroidal anti-inflammatory drugs (NSAIDs), including acetylsalicylate, naproxen, ibuprofen, and etodolac, are used to alleviate pain, swelling, and decrease inflammation. NSAIDs exert their actions by inhibiting the enzymatic activity of the cyclooxygenase (COX) involved in the synthesis of prostaglandins (PG). Inhibition of COX-2 by NSAIDs blocks PG production at sites of inflammation, whereas inhibition of COX-1 in other tissues (platelets and the gastroduodenal mucosa) leads to common adverse effects of NSAIDs, such as bleeding and gastrointestinal ulceration (6). In addition, corticosteroids, like glucocorticoids, are another kind 
of potent anti-inflammatory drug, which modulates gene expression by binding to glucocorticoid receptors to display anti-inflammatory and immunosuppressive effects. However, their side effects include nausea, abdominal pain, ulcers, osteoporosis, and diabetes (7).

Owing to the adverse effects of NSAIDs and corticosteroids, disease-modifying antirheumatic drugs (DMARDs), a class of immunosuppressive and immunomodulatory agents, are developed to prevent and relieve RA aggression. As the first treatment strategy, conventional synthetic (cs) DMARDs like methotrexate, hydroxychloroquine, sulfasalazine, leflunomide, chloroquine, and gold salts should be used as soon as RA is diagnosed. Notably, methotrexate is preferred for use in patients. csDMARDs are popular because of their low price and good efficacies. However, their mechanisms of action are not fully understood and multiple signal pathways could be involved. If a patient shows nonresponse for csDMARDs, biological (b) DMARDs or targeted synthetic (ts) DMARDs should be added. bDMARDs (i.e., adalimumab, infliximab, certolizumab, canakinumab, tocilizumab, sarilumab, and secukinumab) are monoclonal antibodies and have special targets like tumor necrosis factor (TNF)- $\alpha$, interleukin (IL)-6, IL-1 $\beta$, and IL-17 (8-10). tsDMARDs also have special targets, for example, janus kinases (JAK) is the special target of tofacitinib, baricitinib, filgotinib, upadacitinib, and decernotinib (11).

Although the above mentioned DMARDs have been quite successful in mitigating RA, it is still an undeniable fact that a significant proportion of patients could experience treatment failure, including nonresponse and limited efficacy (12). To achieve the maximum therapeutic effectiveness, rheumatologists recommend using combination therapy for RA patients $(13,14)$. For instance, the combination of methotrexate and glucocorticoid can relieve RA in about $25 \%$ of patients within 6 months. If methotrexate plus glucocorticoid is insufficient, any bDMARDs or tsDMARDs can be recommended to add to csDMARDs, such as methotrexate plus tocilizumab, methotrexate plus rituximab, methotrexate plus tofacitinib, and so on (15). Apart from nonresponse, some DMARDs do cause adverse clinical effects, such as stomatitis, exanthema, diarrhea, anemia, pneumonia, and nephritis, further aggravating the disease condition (16-18).

With the deepening of research and exploration, many molecules are identified to exert important roles and bring novel insights to prevent RA. For example, emerging protein targets like IL-4, IL-10, IL-15, IL-17, IL-18, IL-23, interleukin-1 receptor-associated kinase (IRAK)-4 have been revealed to have a strong implication with innate and adaptive immune response in RA (19). Small molecular metabolites, including prostaglandins (PGs), lipoxins (LXs), platelet-activating factor (PAF) and leukotrienes (LTs), nitric oxide (NO), and reactive oxygen species (ROS), are also vital participants and mediators in the physiopathology of RA (20). Besides, an increasing number of studies show that epigenetic regulators play important roles in RA, like non-coding RNAs, DNA methylation, RNA methylation, and histone modifications (21). Up to now, researchers have explored and developed some new agents for $\mathrm{RA}$ according to these classical or emerging targets. This review searched literature published between 2005 and 2021 using keywords cytokines," "chemokines," "protein targets," "small molecular metabolites," and "epigenetics," and summarizes recent advances in these novel targets. The review provides insights that contribute to future directions and drug discoveries for the treatment of RA.

\section{PROTEIN TARGETS FOR TREATMENT OF RHEUMATOID ARTHRITIS}

Currently, many agents aiming at various protein targets have been explored and tested to ease the progression of RA, and some agents have been used in the clinic to treat RA patients (Table 1). In addition to cytokine targets and chemokine targets, several important proteins participate in inflammatory cellular pathways as well, such as JAK and IRAK-4.

\section{Cytokine Targets}

Cytokines have long been explored and studied as potential targets of RA because cytokines are directly involved in the RA process, which can be classified as pro- and anti-inflammatory cytokines based on their different functions against antigen response.

Pro-inflammatory cytokines, including TNF- $\alpha$, IL-1 $\beta$, IL-6, IL-7, IL-15, IL-17, IL-18, IL-23, interferon (IFN)- $\gamma$, granulocytemacrophage colony-stimulating factor (GM-CSF) have been found to govern inflammation in RA occurrence. The level of these cytokines elevated in the synovium, synovial fluid, serum, or peripheral blood of RA patients (61-67). In addition, IL-15, IL-17, IL-23, and GM-CSF have a strong relation to rheumatoid factor (RF), anti-cyclic citrullinated peptide (CCP) seropositivity, and RA activity, which could become diagnostic biomarkers for RA (64, 67-69). IL-7 would also be taken as a diagnostic biomarker for early RA because of the different levels in the stages of RA occurrence (63).

Macrophages can secrete various cytokines, such as TNF- $\alpha$, IL-1 $\beta$, IL-6, IL-7, IL-15, IL-18, IL-23. TNF- $\alpha$ can induce the proliferation of fibroblast-like synoviocytes (FLS) and synovial cells by activating nuclear factor kappa-B $(\mathrm{NF}-\kappa \mathrm{B})$ and extracellular regulated protein kinases (Erk)-1/2-E26 transformation-specific (ETS)-1 signaling pathway, respectively $(70,71)$, resulting in the secretion of a variety of inflammatory mediators like IL-6, matrix metalloproteinases (MMP)-1, and MMP-3 to increase inflammation (72). IL-1 $\beta$ enhances MMPs production and the adhesion of leukocytes to RA FLS by activating ERK, c-Jun N-terminal kinase (JNK), apetala (AP)-1, and NF- $\mathrm{KB}(73,74)$. IL- 6 causes bone resorption and cartilage degeneration by inducing the production of MMPs and NF- $\mathrm{KB}$ ligand (RANKL) receptors $(75,76)$. Blockade of IL-7 ameliorates joint inflammation by reducing $\mathrm{T}$ cells trafficking and proinflammatory factors like TNF- $\alpha$, IL-1 $\beta$, IL-6, and MMPs (77). IL-15 increases the level of major histocompatibility complex (MHC)-II on macrophages to result in enhancing proliferation of antigen-specific cluster of differentiation (CD) $4^{+} \mathrm{T}$ cells (78). IL-18 acts in synergy with IL-12 to stimulate T 
TABLE 1 | Protein targets and their agents in rheumatoid arthritis.

\begin{tabular}{|c|c|c|c|}
\hline Targets & Agents & Phases & References \\
\hline \multicolumn{4}{|l|}{ Cytokines } \\
\hline \multirow[t]{5}{*}{ TNF } & Adalimumab & Marketed & (7) \\
\hline & Infliximab & Marketed & (7) \\
\hline & Etanercept & Marketed & (7) \\
\hline & Certolizumab & Marketed & (7) \\
\hline & Golimumab & Marketed & $(7)$ \\
\hline IL-1R & Anakinra & Marketed & (7) \\
\hline \multirow[t]{3}{*}{$\mathrm{IL}-1$} & Canakinumab & Marketed & (7) \\
\hline & Gevokizumab & Marketed & (7) \\
\hline & Rilonacept & Terminated & Clinicaltrials.gov \\
\hline IL-6R & Tocilizumab & Marketed & (7) \\
\hline \multirow[t]{4}{*}{$\mathrm{IL}-6^{\mathrm{a}}$} & Sarilumab & Marketed & (7) \\
\hline & Clazakizumab & Marketed & (7) \\
\hline & Olokizumab & Marketed & $(7)$ \\
\hline & Sirukumab & Marketed & (7) \\
\hline$\|-2$ & MEDI5117 & Terminated & Clinicaltrials.gov \\
\hline IL-10 & Dekavil & Phase 1 & (22) \\
\hline $\mathrm{IL}-15$ & AMG-714 & Phase 2 & (23) \\
\hline $\mathrm{IL}-18$ & rhlL-18BP & Phase 1 & (24) \\
\hline \multirow[t]{2}{*}{$\mathrm{IL}-17$} & Secukinumab & Phase 3 & (25) \\
\hline & Ixekizumab & Phase 2 & (26) \\
\hline IL-17R & Brodalumab & Terminated & Clinicaltrials.gov \\
\hline $\mathrm{IFN}-\gamma$ & Fontolizumab & Terminated & Clinicaltrials.gov \\
\hline \multicolumn{4}{|c|}{ Chemokines } \\
\hline \multirow[t]{2}{*}{ CCL2 } & p8A MCP-1 & Animal study & $(27)$ \\
\hline & ABN912 & Phase 1 & (28) \\
\hline CCR9 & CCX8037 & Animal study & (29) \\
\hline CX3CL1 & E6011 & Phase 1 & (30) \\
\hline \multirow[t]{6}{*}{ CCR1 } & J-113863 & Animal study & (31) \\
\hline & $\mathrm{BX} 147$ & Animal study & (32) \\
\hline & BAY86-5047 & Phase 2 & Clinicaltrials.gov \\
\hline & ZK811752 & Phase 2 & Clinicaltrials.gov \\
\hline & CCX354 & Phase 2 & (33) \\
\hline & BMS-817399 & Phase 2 & Clinicaltrials.gov \\
\hline \multirow[t]{3}{*}{ CCR2 } & MK-0812 & Phase 2 & Clinicaltrials.gov \\
\hline & MC-21 & Animal study & (34) \\
\hline & MLN1202 & Phase $2 a$ & (35) \\
\hline \multirow[t]{5}{*}{ CCR5 } & SCH-X82 & Phase 2 & (32) \\
\hline & Met-RANTES & Phase 2 & (36) \\
\hline & AZD5672 & Phase 2 & $(37)$ \\
\hline & Maraviroc & Terminated & (38) \\
\hline & SCH351125 & Phase 1b & (39) \\
\hline \multicolumn{4}{|c|}{ Other proteins } \\
\hline TLR4 & $\mathrm{Nl}-0101$ & Phase 2 & Clinicaltrials.gov \\
\hline GRK2 & Paroxetine & Phase 2 & Clinicaltrials.gov \\
\hline MEK & ARRY-162 & Phase 2 & Clinicaltrials.gov \\
\hline MMP-9 & Andecaliximab & Phase 2 & $(40)$ \\
\hline CD3 & Otelixizumab & Phase 1 & $(41)$ \\
\hline CD80 & Abatacept & Marketed & $(42)$ \\
\hline \multirow[t]{3}{*}{ BTK } & ICP-022 & Phase 1 & Clinicaltrials.gov \\
\hline & CC-292 & Phase 2 & (43) \\
\hline & HM71224 & Phase 1 & Clinicaltrials.gov \\
\hline \multirow[t]{2}{*}{$11-23$} & STA 5326 mesylate & Phase 2 & $(44)$ \\
\hline & Guselkumab & Terminated & Clinicaltrials.gov \\
\hline \multirow[t]{5}{*}{ GM-CSF } & Otilimab & Phase 3 & $(45)$ \\
\hline & Gimsilumab & Phase 1 & $(45)$ \\
\hline & Namilumab & Phase 2 & $(45)$ \\
\hline & Mavrilimumab & Phase 2 & $(45)$ \\
\hline & Lenzilumab & Terminated & Clinicaltrials.gov \\
\hline \multicolumn{4}{|c|}{ Chemokines } \\
\hline CXCL10 & MDX-1100 & Phase 2 & $(25)$ \\
\hline CXCL12 & 30D8 & Animal study & (46) \\
\hline CXCL13 & mAb470 & Animal study & $(47)$ \\
\hline
\end{tabular}


TABLE 1 | Continued

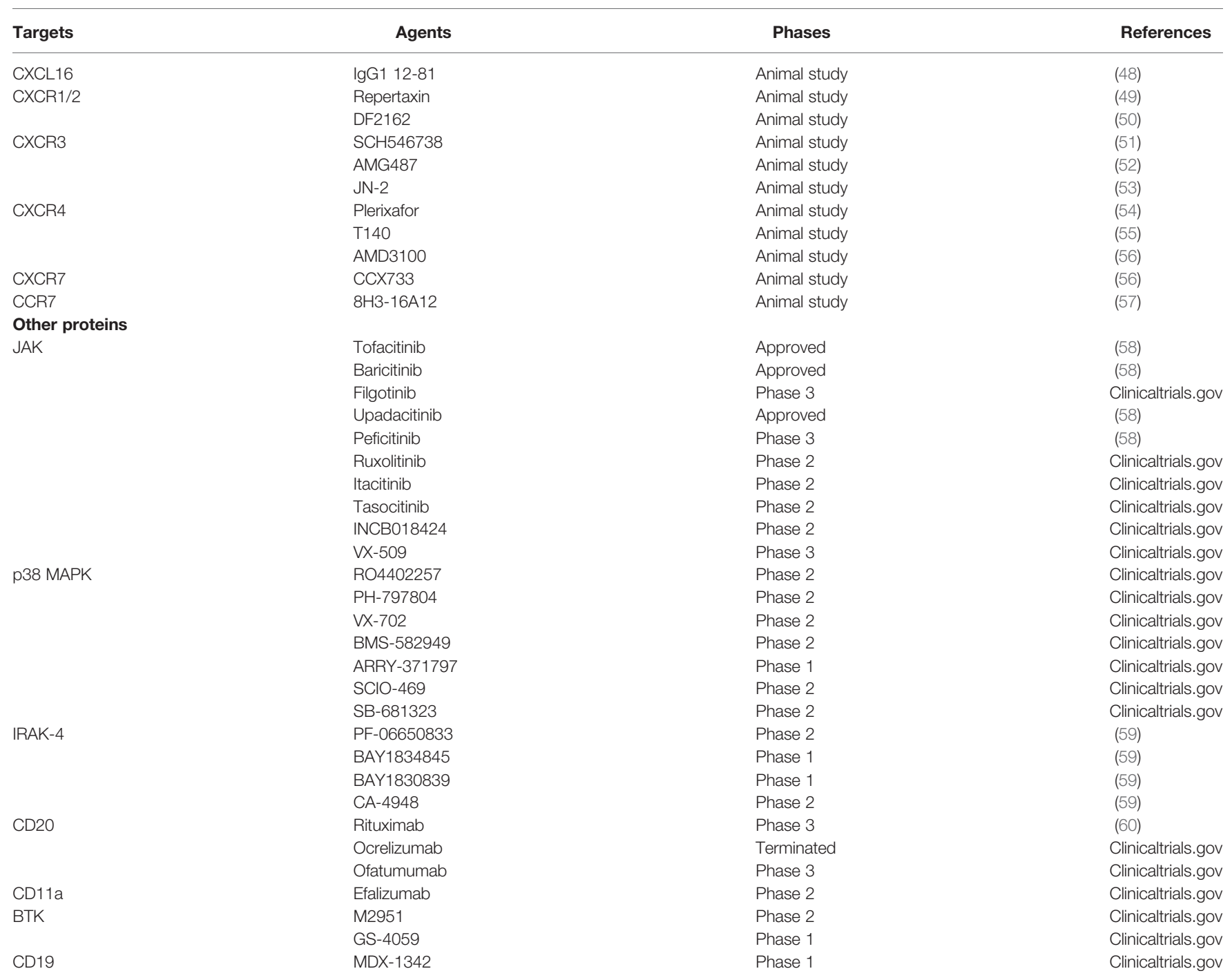

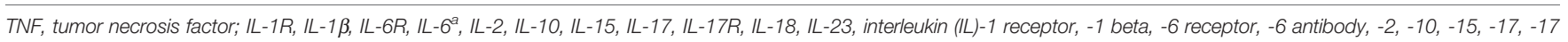

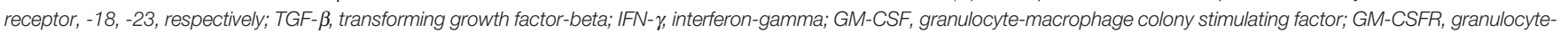

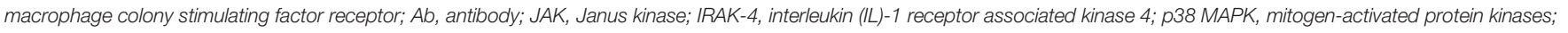
MMP-9, matrix metalloproteinase 9; CD20, CD80, CD3, CD11a, CD19, cluster of differentiation (CD)-20, -80, -3, -11a, -19, respectively; GRK2, G protein-coupled receptor kinase 2;

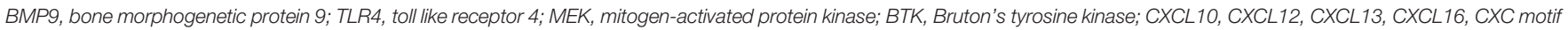
ligand-10, -12, -13, -16; CXCR1/2, CXCR3, CXCR4, CXCR7, CXC motif receptor-1/2, -3, -4, -7; CCL2, CC motif ligand 2; CCR1, CCR2, CCR5, CCR7, CCR9, CC motif receptor-1, -2, -5, $-7,-9 ;$ CX3CL 1, CX3C ligand 1.

cells production of IFN- $\gamma$, which in turn stimulates synovial macrophages to produce TNF- $\alpha$ and IL- $1 \beta$, leading to joint inflammation and cartilage destruction (79). IL-23-induced synovial inflammation is primarily linked to the activation of JAK-STAT, tyrosine kinase $2, \mathrm{NF}-\kappa \mathrm{B}$, and retinoic acid receptorrelated orphan receptors (RORs) (80). IL-17 produced by $\mathrm{T}$ helper (Th) 17 cells upregulates RANKL expression, which is dependent on the IL-17/IL-17 receptor A (IL-17RA)/STAT-3 signaling cascade in FLS (81). IFN- $\gamma$ is produced mainly by nature killing (NK) cells and increases CD31 and vascular cell adhesion molecule (VCAM)-1, resulting in the expansion of innate immune cell infiltration (82). Th1 cells are the predominant Th cell subset to produce GM-CSF, which can upregulate macrophage/monocyte-derived dendritic cells (MoDCs) numbers via GM-CSFR signaling (67). Understanding these mechanisms is beneficial for the development of agents in RA. As Table 1 shows, many agents aiming at different cytokine targets have been developed and applied in practice, such as TNF inhibitors, IL-6 inhibitors, IL-1 inhibitors, IL-15 inhibitors, IL-17 inhibitors, and so on. Most of these agents act as inhibitors to affect downstream pro-inflammatory cytokines by blocking the corresponding targets, reducing symptoms and pain (Figure 1). For example, adalimumab as a TNF inhibitor blocks the bind of TNF and its receptors to reduce cytokines (like MMP-1 and MMP-3)-driven inflammatory processes, which suppresses the destruction of cartilage and bone (72). 


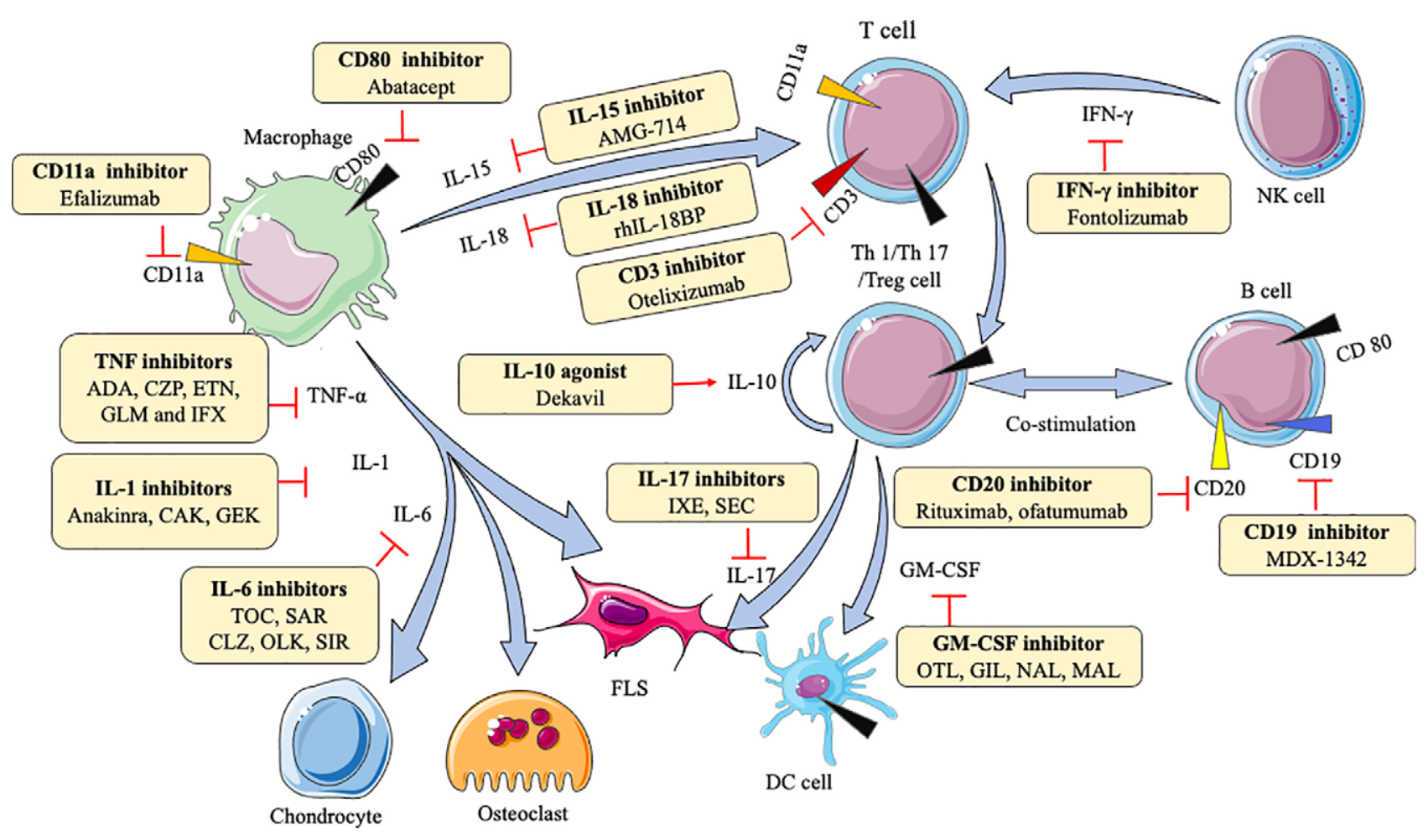

FIGURE 1 | Action of drugs targeting cytokines in rheumatoid arthritis. ADA, adalimumab; CZP, certolizumab; ETN, etanercept; GLM, golimumab; IFX, infliximab; CAK, canakinumab; GEK, gevokizumab; TOC, tocilizumab; SAR, sarilumab; CLZ, clazakizumab; OLK, olokizumab; SIR, sirukumab; OTL, otelixizumab; IXE, ixekizumab; SEC, secukinumab; OTL, otilimab; GIL, gimsilumab; NAL, namilumab; MAL, mavrilimumab; FLS, fibroblast-like synoviocytes; DC, dendritic cell; NK, natural killer cell; TNF- $\alpha$, tumor necrosis factor- $\alpha$; IL-1, IL-6, IL-10, IL-15, IL-17, IL-18, interleukin (IL)-1, -6, -10, -15, -17, -17, respectively; IFN- $\gamma$, interferon-gamma; GM-CSF, granulocyte-macrophage colony stimulating factor.

On the other hand, several cytokines, including IL-4, IL-10, IL-13, and TGF- $\beta$, exert anti-inflammatory effects in RA. Unsurprisingly, serum IL-10 level is remarkably lower in RA patients (83). A higher expression of IL-4 and IL-13 is uncovered in the synovial fluid of early RA rather than established RA, which means IL-4 and IL-13 would be the diagnostic biomarkers for early RA patients $(84,85)$. However, the level of TGF- $\beta$ is high in the FLS and synovial fluids from RA patients $(86,87)$.

As anti-inflammatory factors, the injection of L-4, IL-10, IL-13, TGF- $\beta$, or their agonist can play therapeutic roles. IL-4 secreted by activated $\mathrm{T}$ cells has anti-angiogenic effects by inhibiting VEGF production in RA FLS, which helps relieve RA (88). IL-10, produced by regulatory $T$ (Treg) cells, suppresses Th17 cells and promotes Treg cells in the $\mathrm{CD}^{+} \mathrm{T}$ cells population (89). IL-13 is a cytokine of Th2 cell-mediated immune response. IL-13 exerts its anti-angiogenic function via activation of protein kinase $\mathrm{C}$ (PKC) $\alpha / \beta$ II and ERK-1/2, with concomitant down-regulation of the NF- $\kappa \mathrm{B} / \mathrm{p} 65$ pathway (90), and it also can reduce the death of chondrocytes to protect the cartilage from destruction probably because of the reduction of Fc gamma receptor I (Fc $\gamma R I)$ (91). Transforming growth factor (TGF)- $\beta$ is principally expressed by macrophages and $\mathrm{T}$ lymphocytes. TGF- $\beta 1$ promotes FLS migration and invasion by inducing epithelial-mesenchymal transition (EMT) via activating Smad-2/3 in RA (92). Clinical trials observed that dekavil (an agonist of IL-10) shows a significant efficacy in RA patients (93) (Figure 1). These types of agents (agonist) can bind and initiate receptors to induce corresponding target reactions.

\section{Chemokine Targets}

It is reported that chemokines are involved in the underlying pathogenesis of RA by recruiting leukocyte and affecting angiogenesis. Chemokines are divided into four categories based on different structures, which are as follows: CXC chemokines, CC chemokines, $\mathrm{XC}$-chemokines, and CX3C chemokines.

CXC chemokines, including CXCL1, CXCL2, CXCL5, CXCl6, CXCL8, CXCl9, CXCL10, CXCL12, CXCL13, and CXCL16, have been identified with abnormal expression levels in synovial fluids, synovial tissues, fibroblasts, and endothelial cells of RA patients $(2,94,95)$. In addition, CXC chemokine receptors also implicate in RA, such as CXCR1, CXCR2, CXCR3, CXCR4, CXCR5, CXCR6, and CXCR8. The level of these receptors is higher in RA patients than in healthy controls (96-98).

CXC chemokines,like CXCL1, CXCL2, CXCL5, CXCL8, CXCR1, and CXCR2, generally, are involved in neutrophil chemotaxis (99), but CXCL10 and CXCL13 promote effector T 
cells and B cells recruitment into the joint, respectively (100, 101). CXCL12, CXCL16, and CXCR6 increase the endothelial progenitor cell recruitment and blood vessel formation in the RA joint (102). CXCR3, CXCR4, and CXCR5 enhance Th1 cells, lymphocytes, B cells, and T follicular helper (Tfh) cells into joint, respectively (100, 103). However, CXCL9 can diminish neutrophil recruitment of joints (104). As shown in Table 1, inhibitors or antagonists of these targets have shown good results in animals, such as CXCR3, CXCR4, CXCL10, CXCL12, and CXCL13, especially the antibody of CXCL10 (MDX-1100) has entered clinical trials (25) (Figure 2).

CC chemokines including CCL2, CCL3, CCL4, CCL5, CCL7, CCL13, CCL14, CCL16, CCL18, CCL19, CCL20, CCL21, and CCL25 are abnormally expressed in plasma and synovia in RA. Levels of some CC chemokines are significantly correlated with the swollen joints, erythrocyte sedimentation rate (ESR), creaction protein (CRP), like CCL2, CCL5, CCL17, CCL18, CCL19 (105-107). Besides, the synovium also is rich in CCR1, CCR2, CCR3, CCR4, CCR5, CCR6, CCR7, CCR9, and CCR10 in RA (96, 108-112). CCR2, CCR4, and CCR6 are proven to positively implicate disease activity in RA $(113,114)$.

In RA, CCL2, CCL3, CCL4, CCL5, CCL7, CCR1, CCR2, CCR5-7, CCR9, and CCR10 induce monocytes to enter the joint synovial. CCL18, CCL19, CCL20, CCL21, CCL25, CCR5, and CCR6 recruit T cells into the joint. CCL20 induces B cells, and CCL14, CCL16, CCR3 recruit endothelial cells to enter into the inflamed joint (115-118). CCL13 has chemoattractant activity for both human myeloid leukemia mononuclear cells and human umbilical vein endothelial cells (119). CCR4 can attract skin-specific memory $\mathrm{T}$ cells to enter the joints (120). CCR9 can also increase the number of dendritic cells in the joint (116). Researchers find blocking or reducing these CC chemokines and their receptors, such as CCL2, CCL3, CCL5, CCL7, CCR1-5, CCR9, and CCR10, can ameliorate tissue swelling and bone erosion (27, 29, 121-124). Among them, CCL2, CCR1, CCR2, and CCR5 have achieved good clinical results $(28,33,35,37,39,125,126)$ (Figure 2).

$\mathrm{XC}$ - chemokines and their receptors (like XCL1, XCR1), $\mathrm{CX} 3 \mathrm{C}$ chemokines and their receptors (like CX3CL1 and CX3CR1) have an up-regulation in mononuclear cells (MNCs) and FLS, respectively, in RA patients $(98,127)$. Many inflammatory chemokines are mainly produced by synovial macrophages and FLS in the joints of RA patients, whereas CX3CL1 is produced by synovial endothelial cells. XC and CX3C chemokines are involved in the recruitment of $\mathrm{T}$ cells and synovial fibroblasts. Moreover, CX3CL1 and XCL1 also promote the migration of monocytes and subchondral mesenchymal progenitor cells, respectively, into RA synovium

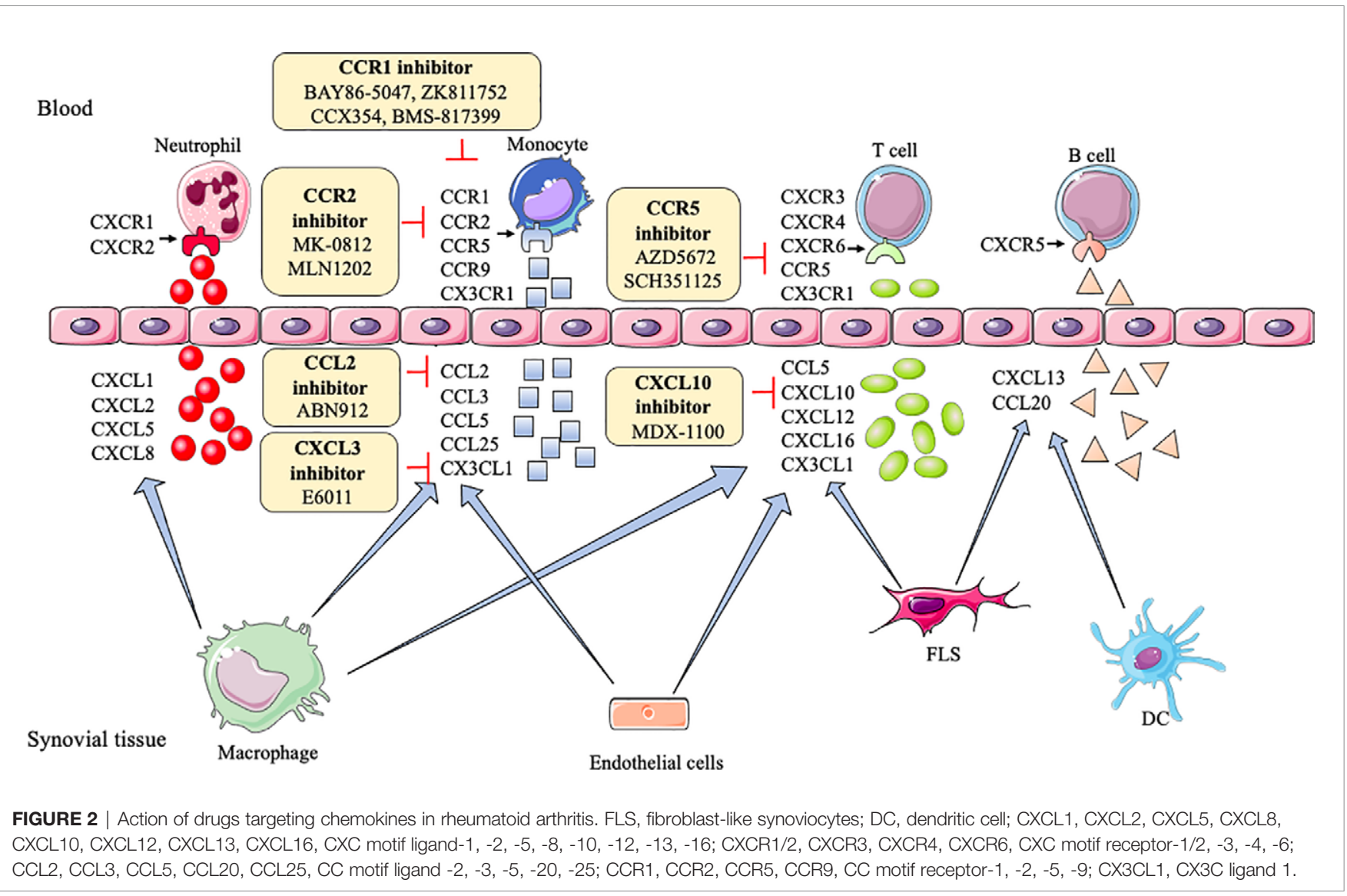


$(128,129)$. Currently, a clinical trial of E6011 (an anti-CX3CL1 $\mathrm{mAb}$ ) has been demonstrated to have a promising role in active RA patients (30) (Figure 2).

\section{Other Protein Targets}

Similar to the cytokine targets described above, many other important proteins also play remarkable roles in the pathogenesis of RA, and corresponding agents have been used in clinical settings as part of continuous research into treating RA (Table 1).

In a large number of experiments, JAK, p38 mitogenactivated protein kinase (MAPK), ERK, JNK, IRAK-4, MMPs, toll-like receptor (TLR)-4, G protein-coupled receptor kinase (GRK)-2, Bruton's tyrosine kinase (BTK), CD3, CD11a, CD19, $\mathrm{CD} 20$, and CD80 are demonstrated as examples of such important proteins in RA. JAK are a part of the JAK/STAT pathway, and this signaling is continuously activated, resulting in the elevated level of MMPs and apoptotic chondrocytes in RA synovial joints (130). p38 MAPK, ERK, and JNK activations are almost exclusively found in synovial. As a member of the MAPK family, p38MAPK, ERK, JNK are activated by MAPKK to influence pro-inflammatory cytokines, such as TNF, IL-6, and IL-1 (131). Specifically, p38MAPK may phosphorylate MAPKAP2, which in turn affects downstream cells (132). JNK involves in effector $\mathrm{T}$ cells function by stimulating Th1 differentiation in RA synovial tissue (131). IRAK-4 is an essential protein kinase in mediating pathogen recognition and local cytokine release (like IL-1, IL-6, TNF) through TLR and IL$1 \mathrm{R}$ signaling. Furthermore, the activity of IRAK-4 kinase regulates Th17-mediated autoimmune diseases like RA through the involvement of Th17 differentiation (133). MMPs break cartilage and bone by degrading all components of the extracellular matrix (134). TLR4 can enhance the production of pro-inflammatory cytokines and chemokines, such as IL-6 and IL-17, by binding with exogenous ligands, like peptidoglycan, in FLS and peripheral blood mononuclear (PBMC) from RA patients, and trigger cartilage inflammation and degeneration (135). GRK2 prevents the shift of M1 into M2 macrophages by mediating PGE2-EP4-cAMP-CREB signaling in synovial macrophages (136). BTK activation induces B cells survival, proliferation, and differentiation by the SYK-BTK axis (137), which is an attractive therapeutic target for RA. CD3 expressed by mature $\mathrm{T}$ cells and thymocytes can activate $\mathrm{T}$ cells signaling and regulate TCR expression by the formation of $\mathrm{T}$ cell receptor (TCR)/CD3 complex (138). As an adhesion molecule, CD11a can facilitate the recruitment and entry of $\mathrm{T}$ cells into the synovial tissue via LFA-1(CD11a/CD18)/intercellular cell adhesion molecule (ICAM)-1 pathway (139). CD19 amplifies the activation of Lyn and Src-family protein tyrosine kinases, thereby enhancing the signals generated by the B-cell antigen receptor to regulate $\mathrm{B}$-cell development, activation, and differentiation (140). Although the biological activity of CD20 and CD80 are not fully elucidated, CD20 allows specific and effective B-cell depletion and CD80 involves in $\mathrm{T}$ cell co-stimulation (141). Inhibitors for these abovementioned protein targets have entered clinical trials (Figure 1).

\section{SMALL MOLECULAR METABOLITE TARGETS FOR TREATMENT OF RHEUMATOID ARTHRITIS}

Previous research has shown that small molecular metabolites, like PGs, LTs, LXs, PAF, ROS, and NO, support to induce, maintain, or relieve inflammation in RA (20). Therefore, such compounds could be potential therapeutic targets (Table 2).

\section{PGs Targets}

In some reports, the key function of PGs is shown in physiological immune responses and pathological conditions related to inflammation and tissue damage. The expressions of PGs, including PGD2, PGE2, PGF2 $\alpha$, PGI2, PGJ2, and TXA2, are abnormal in RA (20). It is worth noting that PGD2 and PG/2 are anti-inflammatory small molecules. The binding of PGD2 to DP1(a PGD receptor) inhibits IL-1-induced production of MMP-1 and MMP-13 by chondrocytes (160). It is likely that PGJ2 decreases the production of IL- $1 \beta$ and reactive oxygen species (ROS) through the NF- $\mathrm{KB}$ pathway (146). 15d-PGJ2, as the metabolite of PGD2, ameliorates disease through the suppression of Th17 cells and the induction of $\mathrm{CD} 4^{+} \mathrm{CD} 25^{-} \mathrm{FOXP} 3{ }^{+}$cells (146). PGE2 enhances cyclic AMP production by an EP4 (a PGE2 receptor)-dependent mechanism to increase immune inflammation (161). Although the mechanism of PGF2 $\alpha$ in RA is unclear, it can prevent cell proliferation, inflammation, tissue remodeling via MMP-3, and angiogenesis via VEGF (147). PGI2 probably increases Th2 cell function by IP (PGI2 receptor) to reduce the production of IL-1 $\beta$, IL-6, and monocyte chemoattractant protein (MCP)-1 (162). The TP receptor antagonist (SQ29548) inhibits both cyclooxygenase (COX)-2 expression and FLS proliferation, and TP agonist U46619 enhances them. Therefore, TXA2 exerts its function probably through the IP-COX-2 pathway (148) (Figure 3).

\section{LTs Targets}

In the LTs family, LTB-4 and cysteinyl (Cys)LT- 1 are involved in the inflammatory response of RA. Synovial fluid LTB4 levels are upregulated in RA patients. Although the underlying mechanism of LTs is not rather clear, some trials show their function in RA. The major effect of LTB4 and its receptor is to enhance the movement of leucocytes from the circulation toward the site of tissue damage (163). An antagonist of LTB4 receptor, BIIL 284 inhibits the LTB4-stimulated expression of Mac-1 on neutrophils in RA patients (164). A potent CysLT1 receptor antagonist, montelukast inhibits the activation of the NF- $\mathrm{\kappa B}$ pathway and secretion of IL-6 and IL- 8 in FLS (165), next to reducing the disease incidence and its activity (166). These results mean that the inhibition of CysLT1 and LTB4 receptors would be a potential and promising new therapeutic method to prevent inflammation and disease progression in RA patients (Figure 3).

\section{LXs Targets}

The family of LXs, like LXA4 and LXB4, generated from arachidonic acid display anti-inflammatory activities. LXA4 can decrease memory B-cell response via engagement of lipoxin A4 receptor (ALX)/formyl peptide receptor-2 (FPR-2) in synovial 
TABLE 2 | Small molecular metabolite targets and their agents in rheumatoid arthritis.

\begin{tabular}{|c|c|c|c|}
\hline Targets & Agents & Phases & References \\
\hline \multicolumn{4}{|c|}{ PGs targets } \\
\hline PGD2 & MK0524 & Animal study & $(142)$ \\
\hline \multirow[t]{2}{*}{ PGE2 } & ER-819762 & Animal study & (143) \\
\hline & CR6086 & Animal study & (144) \\
\hline PGl2 & lloprost & Phase 2 & $(145)$ \\
\hline PGJ2 & 15d-PGJ2 & Animal study & (146) \\
\hline PGF2 $\alpha$ & AL-8810 & Animal study & (147) \\
\hline TXA2 & SQ29548 & Animal study & (148) \\
\hline \multicolumn{4}{|c|}{ LTs targets } \\
\hline LTB4R & BIIL 284 & Phase 1 & (149) \\
\hline CysLT1R & Montelukast & Animal study & (150) \\
\hline \multicolumn{4}{|c|}{ LXs targets } \\
\hline ALX & BML-111 & Animal study & $(151)$ \\
\hline \multicolumn{4}{|c|}{ PAF targets } \\
\hline PAFR & WB2086 & Animal study & (152) \\
\hline \multicolumn{4}{|c|}{ ROS targets } \\
\hline \multirow[t]{2}{*}{ ROS } & Cinnamaldehyde & Cell culture & (153) \\
\hline & Eugenol & Cell culture & (153) \\
\hline \multicolumn{4}{|c|}{ NO targets } \\
\hline \multirow[t]{2}{*}{ iNOS } & GW274150 & Phase 2 & (154) \\
\hline & L-NAME & Animal study & (155) \\
\hline \multicolumn{4}{|c|}{ Other small molecular targets } \\
\hline \multirow[t]{2}{*}{ CB2 } & HU-308 & Animal study & $(156)$ \\
\hline & JWH-015 & Animal study & $(157)$ \\
\hline \multirow[t]{2}{*}{$\mathrm{FFAH}$} & URB597 & Animal study & (158) \\
\hline & NAGly & Animal study & (159) \\
\hline
\end{tabular}

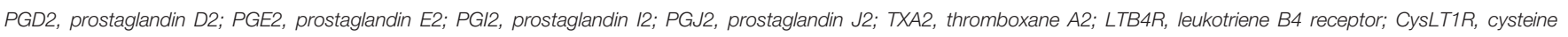

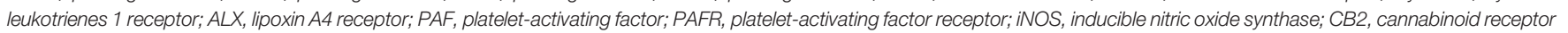
2; FFAH, specific fatty acid amide hydrolase; NAGly, N-arachidonic glycine.

tissues of patients with RA, further enhancing the reduction of inflammation (167, 168). BML-111 (an ALX/FPR2 agonist) partly downregulates the immune response in CIA (151). LXB4 has antiinflammatory effects by regulating the adhesion and motility of monocytes and neutrophils and enhancing antibody production by human memory B cells $(47,169)$ (Figure 3).

\section{PAF Targets}

Studies suggest that PAF plays a prominent role in RA. The activation of circulating platelets further influences leukocyte activity and participates in inflammation formation in RA patients (170). It is reported that pathways based on TNF- $\alpha$ regulate PAF, and TNF- $\alpha$ antagonists inhibit platelet activation in active patients with RA (171). WB2086, a human PAF receptor antagonist, inhibits PAF-induced platelet aggregation in animal models (152). Based on current studies, targeted agents inhibiting $\mathrm{PAF}$ and its receptor needed more research because of the limitation of experience with the therapeutic effects of this target.

In these mechanisms of PGs, LTs, LXs, PAF, receptors play significant roles, therefore inhibitors or agonists of these receptors can exert therapeutic functions, and the therapeutic effects are proven in animal experiments (Figure 3).

\section{ROS and NO Targets}

ROS and NO belong to oxidant molecules, which involve in the pathogenesis of many chronic autoimmune diseases, including RA. There is a strong positive correlation between serum ROS level and disease severity in both RA patients and arthritic rodent models (172). ROS regulates MAPK and NF- $\mathrm{KB}$ signaling pathways, further affecting cell proliferation, angiogenesis, and apoptosis in joints (173). NO and inducible nitric oxide synthase (iNOS) expressions are changed in patients with RA (174). NO regulates $\mathrm{T}$ and $\mathrm{B}$ cells infiltration by inhibiting their chemotaxis and adhesion into joints (175). Treatments with the NOS inhibitor L-NAME and iNOS inhibitor GW274150 are proven to improve inflammation response, and a trend toward a reduction in synovial thickness is observed $(154,155)$.

\section{Other Small Molecular Targets}

The receptor activation of cannabinoid (CB)-1/2 involves the production of endocannabinoids, subsequently, endocannabinoids are quickly metabolized by specific fatty acid amide hydrolase (FAAH) (176). The levels of CB1 and CB2 increase in the synovial membrane with RA. CB2 inhibits IL- $1 \beta$-induced proliferation of RA FLS and the activation of MAPK pathway (157). In addition, the reduction of arthritis severity and activity in FAAH knock-down mice is observed (158). Similarly, the treatment with URB597 and Narachidonic glycine (FAAH inhibitors) prevents the occurrence of CIA in mice as well $(158,159)$. These results mean that the new agents targeting the endocannabinoid system are potential and promising therapeutics for further research.

\section{EPIGENETIC TARGETS FOR TREATMENT OF RHEUMATOID ARTHRITIS}

Epigenetic modifications can regulate gene expression without altering the DNA sequence. Non-coding RNAs (ncRNAs) 


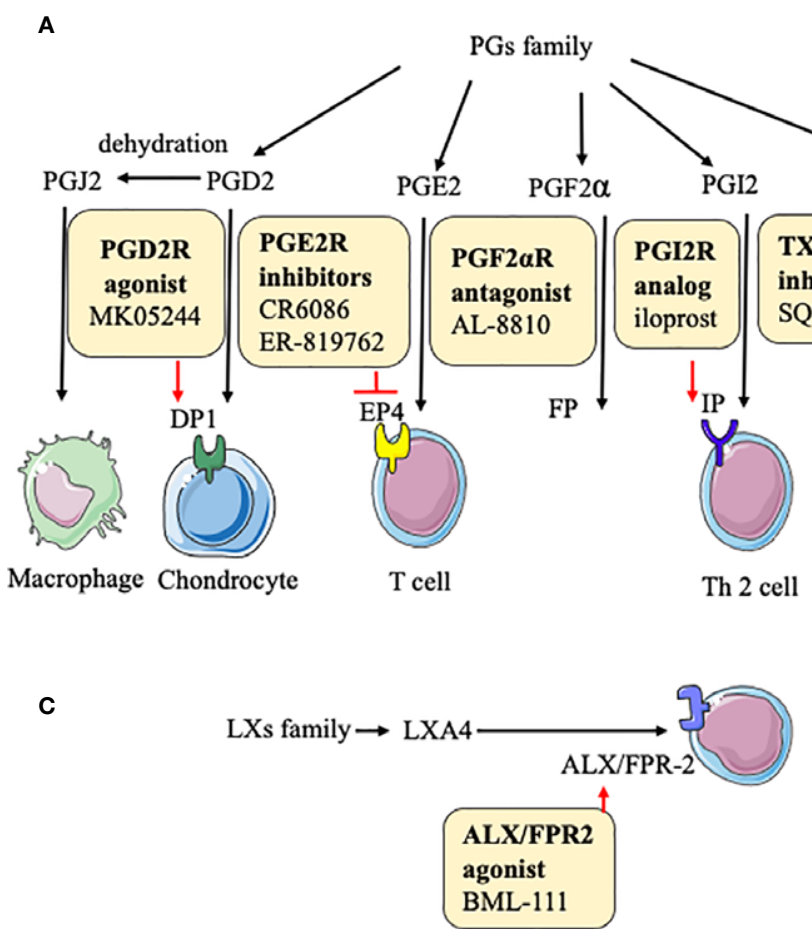

B

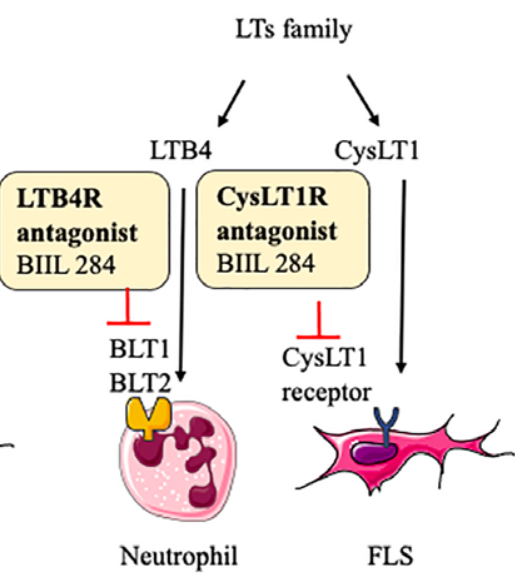

D

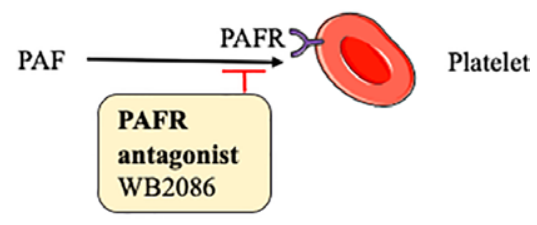

FIGURE 3 | Action of drugs targeting small molecular metabolites in rheumatoid arthritis. (A) action of drugs targeting PGs family in rheumatoid arthritis; (B) action of drugs targeting LTs family in rheumatoid arthritis; (C) action of drugs targeting LXs family in rheumatoid arthritis; (D) action of drugs targeting PAF in rheumatoid arthritis. PGD2, prostaglandin D2; PGE2, prostaglandin E2; PGI2, prostaglandin I2; PGJ2, prostaglandin J2; TXA2, thromboxane A2; PGF2 $\alpha$, prostaglandin F2 $\alpha$; DP1, prostaglandin D2 receptor 1; EP4, prostaglandin E receptor 4; TP, prostaglandin TXA2 receptor; FP, prostaglandin PGF2 $\alpha$ receptor; IP, prostaglandin PGI2 receptor; LTB4, leukotriene B4; CysLT1, cysteine leukotrienes 1; ALX, lipoxin A4 receptor; FPR-2, formyl peptide receptor-2; PAF, platelet-activating factor; PAFR, platelet-activating factor receptor; iNOS, inducible nitric oxide synthase.

regulation, DNA methylation, RNA methylation, and histone modifications are seen as the main mechanisms of epigenetic regulations. Numerous research has established that several abnormalities in these mechanisms eventuate in the development of RA. Corresponding target agents have been applied for patients (Table 3).

\section{ncRNAs}

With the increasing advancement of bioinformatics analysis and microarray sequencing techniques, tremendous ncRNAs are identified in different tissues. Compared with healthy individuals, aberrant levels of abundant ncRNAs are observed, including microRNAs (miRNAs), long non-coding RNAs (lncRNAs), and circular RNAs (circRNAs). Because a large number of ncRNAs especially miRNAs are found, ncRNAs involved in the development and progression of RA are summarized in this review since 2019 sourcing from PubMed (Table 4).

miRNAs are small, mature, non-coding RNA molecules (about 22 nucleotides long) that can affect the processing of target mRNAs at the post-transcriptional level by translational inhibition or promoting mRNA degradation (281). Accumulating studies have revealed that altered expression and dysregulation of miRNAs have something to do with RA occurrence. miRNA-23b, miR-221/222 levels positively correlate with the ESR, rheumatoid factor (RF), CRP, disease activity score (DAS), and anti-citrullinated protein antibodies (ACPA), which will become promising targets for RA detection $(31,204)$. miR-16 and miR-223 are also identified as targets to distinguish patients with early RA from healthy individuals (34).

Most of the aberrant miRNA levels can alter the secretion of inflammatory cytokines or MMPs, further affecting the procession of RA. In FLS, miR-34a-3p (193), miR-129-5p (202), miR-410-3p (207), miR-506 (208), miR-22 (213), miR101-3p (216), miR-495 (217), miRNA-17-5p (218), miRNA-1405p (219), miR-21 (223), miRNA-15a/16 (224), miR-9 (230), miR-20a (234), miR-145-5p (235), miR-365 (236), and miR124a (238) overexpression significantly inhibit the proliferation and promote apoptosis by aiming different proteins or other targets. On the contrary, miR-138 (192), miR-142-3p (198), miR98 (201), miR-26a-5p (203), miR-191 (205), miR-15 (222), and miR-483-3p (282) enhance the inflammatory milieu and subsequently tissues could be damaged. Moreover, miRNA486-5p upregulation in exosomes can repress FLS proliferation and migration, which proves exosomes to be a suitable vector for the delivery of therapeutic miRNA-486-5p (283).

As shown in Table 4, miRNA levels change various intracellular pathways, and the most prominent implicated pathways are those of NF- $\mathrm{KB}(192,198,207,212,213,222$, 229, 230, 238), PI3K/Akt (194, 199, 203, 236), JAK/STAT (218, 
TABLE 3 | Epigenetic targets and their agents in rheumatoid arthritis.

\begin{tabular}{|c|c|c|c|}
\hline Targets & Agents & Phases & References \\
\hline \multicolumn{4}{|c|}{ DNA methylation } \\
\hline \multirow[t]{5}{*}{ DNMT } & Azacitidine & Animal study & $(177)$ \\
\hline & Decitabine & Animal study & (177) \\
\hline & Procainamide & Animal study & (177) \\
\hline & Hydralazine & Animal study & (177) \\
\hline & EGCG & Animal study & $(177)$ \\
\hline \multicolumn{4}{|c|}{ RNA methylation } \\
\hline METTL3 & - & Cell culture & $(178)$ \\
\hline \multicolumn{4}{|c|}{ Histone modification } \\
\hline \multirow[t]{2}{*}{ HAT } & Delphinidin & Cell culture & $(179)$ \\
\hline & Anacardic acid & Animal study & $(180)$ \\
\hline \multirow[t]{2}{*}{ HMT } & GSK-J4 & Animal study & (181) \\
\hline & $\mathrm{EZH} 2$ & Cell culture & \\
\hline \multirow[t]{2}{*}{ HDAC } & MS-275 & Animal study & (182) \\
\hline & Entinostat & Cell culture & (183) \\
\hline \multicolumn{4}{|c|}{ Histone modification } \\
\hline \multirow[t]{12}{*}{ HDAC } & Ml192 & Cell culture & (183) \\
\hline & Trichostatin A & Cell culture & (183) \\
\hline & Valproic acid & Animal study & (183) \\
\hline & Vorinostat & Cell culture & (183) \\
\hline & Nicotinamide & Cell culture & (184) \\
\hline & MPT0G009 & Animal study & (183) \\
\hline & CKD-506 & Animal study & $(185)$ \\
\hline & CKD-L & Animal study & (186) \\
\hline & NK-HDAC-1 & Animal study & $(187)$ \\
\hline & SAHA & Animal study & (182) \\
\hline & Largazole & Cell culture & (188) \\
\hline & Givinostat & Cell culture & (189) \\
\hline \multirow[t]{2}{*}{ BET } & I-BET151 & Animal study & (190) \\
\hline & JQ1 & Animal study & (191) \\
\hline
\end{tabular}

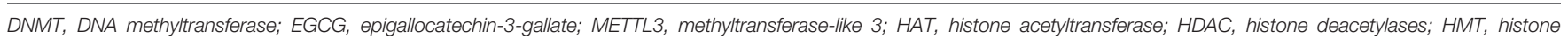
methyltransferase; BET, bromodomain and extra-terminal; SAHA, suberoylanilide hydroxamic acid; EZH2, zeste homolog 2.

219), $\operatorname{TLR}(208,220), \beta$-catenin $(215,217,235)$, and Wnt $(223,235)$. In parallel, the efficacy of several miRNAs against RA has been verified in animal experiments. Injections of miR-141-3p agomir, miR-411 mimics, miR-9, miR-21 lentivirus, miR-26a, miRNA-147 mimics have been proven to ameliorate cartilage injury and bone erosion, further inhibiting inflammatory arthritic development in CIA animal models $(223,226,229,230,284)$. On the other hand, miRNA-17-5p lipoplex and miR-145-5p agomir given to mice are found to increase inflammatory cytokine levels (MMP-3, MMP-9, MMP $-13)$, aggravating arthritis in the future $(212,236)$. The abovementioned studies about the mechanism of miRNAs have shown promising results in experimental models of arthritis, and their efficacy needs more clinical trials to prove.

Consisting of more than 200 nucleotides in length, lncRNAs are identified as long non-coding RNAs and are widely expressed in various tissues of the human body. Many studies have suggested lncRNA could become a diagnostic tool for RA. For example, lncAL928768.3 and lnc-AC091493.1 are positively associated with CRP, DAS, and RF (260). Apart from those two, lncRNA ENST00000483588, ENST00000456270, RNA143598, RNA143596, HIX0032090, IGHC $\gamma 1$, and XLOC_002730 could also become targets to diagnose RA (285-287).

lncRNA FER1L4 and MEG3 regulate RA via targeting nucleotide oligomerization domain-like receptors 5 (NLRC5) in RA FLS $(263,288)$. Overexpression of lncRNA MEG3 plays an anti-inflammatory effect by regulating the AKT/mTOR signaling pathway (258). IncRNA PICSAR alters cell proliferation, migration, invasion, IL-6, IL-8, and MMP-3 production through sponging miR-4701-5p, in other words, lncRNA PICSAR can competitively combine miR-4701-5p to affect downstream target genes (257). As a competitive endogenous RNAs (ceRNA), lncRNA HIX003209 exaggerates inflammation through sponging miR-6089 via TLR-4/NF- $\kappa \mathrm{B}$ pathway in RA macrophages (262). miR-222-3p/Sirt1 axis is also found to be critical for the function of lncRNA GAS5 in mitigating the proliferation, inflammation, and apoptosis of RA FLS (289). In particular, lncRNA NEAT1 and lncRNA HAND2AS1 are found in PBMC and mesenchymal stem cells (MSC), respectively, and are involved in the regulation of RA $(241,255)$.

In an arthritic model experiment, silencing lncRNA ZFAS1 can mitigate inflammation and hyperplasia by competitively binding to miR-296-5p and regulating MMP-15 expression (249). Additionally, injecting lentivirus expressing shRNA for IncRNA-H19 intra-articularly at the ankle of CIA mice ameliorates the progression of CIA by competitively binding with miR-124a, which directly targets CDK2 and MCP-1 (267). The injection of lentivirus carrying sh-lncRNA XIST plasmids reduces levels of TNF- $\alpha$, IL-2, and IL- 6 to suppress inflammatory and damage in cartilage tissues (270). Taken together, these 
TABLE 4 | NcRNAs targets in rheumatoid arthritis.

\begin{tabular}{|c|c|c|c|c|c|}
\hline NcRNAs & Expression & Tissue & Signalings & Phases & References \\
\hline \multicolumn{6}{|l|}{ miRNAs } \\
\hline $\operatorname{miR}-138$ & Up & FLS & NF-кB signaling & Cell culture & (192) \\
\hline miR-34a-3p & Down & FLS & - & Animal study & (193) \\
\hline miR-23b & Up & FLS, STS & - & - & $(31)$ \\
\hline miR-125 & Down & ST & PI3K/Akt/mTOR pathway & Cell culture & (194) \\
\hline miR-27b-3p & Down & ST & HIPK2 signaling & Cell culture & (195) \\
\hline \multirow[t]{2}{*}{ MiR-19a-3p } & Up & ST & IGFBP5 signaling & Cell culture & $(196)$ \\
\hline & Down & Plasma & socs3 & Cell culture & (197) \\
\hline miR-142-3p & Up & ST, FLS & $\mathrm{NF}-\kappa \mathrm{B}$ signaling & Cell culture & (198) \\
\hline miRNA-135a & Up & ST & PI3K/AKT pathway & Cell culture & (199) \\
\hline miR-192-5p & Down & BM-MSC-exos & - & - & $(200)$ \\
\hline miR-98 & Up & FLS & IL-10 signaling & Cell culture & $(201)$ \\
\hline$m i R-129-5 p$ & Down & FLS & IGF-1R/SRC/ERK/EGR-1 pathway & Cell culture & $(202)$ \\
\hline miR-26a-5p & Up & FLS & PTEN/PI3K/AKT pathway & Cell culture & $(203)$ \\
\hline miR-221/222 & Up & PBMC & - & - & $(204)$ \\
\hline miR-191 & Up & FLS & miR-191-C/EBP $\beta$ pathway & Cell culture & $(205)$ \\
\hline $\operatorname{miR}-449 a$ & Down & ST & HMGB1 signaling & Cell culture & (206) \\
\hline $\operatorname{miR}-410-3 p$ & Down & SF, FLS & NF-кB signaling & Cell culture & $(207)$ \\
\hline miR-506 & Down & ST, FLS & TLR4 signaling & Cell culture & $(208)$ \\
\hline miR-320a & Down & ST & MAPK-ERK1/2 pathway & Cell culture & $(209)$ \\
\hline miR-29b & Up & PBM & HBP1 signaling & Cell culture & (210) \\
\hline miR-155 & Up & ST & FOXO3a signaling & Cell culture & $(211)$ \\
\hline miR-145-5p & Up & FLS & $\mathrm{NF}-\kappa \mathrm{B}$ pathway & Animal study & $(212)$ \\
\hline \multirow[t]{2}{*}{$\operatorname{miR}-22$} & Down & FLS & IL6R signaling/NF- $\kappa B$ pathway & Cell culture & $(213)$ \\
\hline & Down & ST & SIRT1 signaling & Cell culture & $(214)$ \\
\hline miRNA-141-3p & Down & FLS & FoxC1/ $\beta$-catenin axis & Animal culture & $(215)$ \\
\hline miR-101-3p & Down & FLS & PTGS2 signaling & Cell culture & $(216)$ \\
\hline miR-495 & Down & FLS & $\beta$-catenin pathway & Cell culture & $(217)$ \\
\hline miRNA-17-5p & Down & FLS & JAK/STAT pathway & Animal study & $(218)$ \\
\hline miRNA-140-5p & Down & FLS & STAT3 signaling & Cell culture & $(219)$ \\
\hline miR-3926 & Down & FLS & TLR 5 signaling & Cell culture & $(220)$ \\
\hline miR-613 & Down & FLS, ST & DKK1 signaling & Cell culture & $(221)$ \\
\hline miR-15 & Up & FLS & $\mathrm{NF}-\kappa \mathrm{B}$ pathway & Cell culture & $(222)$ \\
\hline miR-21 & Down & FLS & Wnt pathway & Animal study & $(223)$ \\
\hline miRNA-15a/16 & Down & FLS & sox5 axis & Cell culture & $(224)$ \\
\hline miRNA-155 & Up & FLS & - & - & $(225)$ \\
\hline miR-26a & Down & $\mathrm{CT}, \mathrm{AC}$ & CTGF signaling & Animal study & $(226)$ \\
\hline miR-106b & Down & SFDE & PDK4 signaling & Cell culture & $(227)$ \\
\hline miR-223 & Up & FLS & - & - & $(228)$ \\
\hline $\mathrm{miR}-411$ & Down & ST, FLS & NF-кB pathway & Animal study & $(229)$ \\
\hline miR-9 & Down & FLS & NF-кB1-RANKL pathway & Animal study & $(230)$ \\
\hline miRNA-486-5p & Down & FLS-exos & Tob1/BMP/Smad pathway & Animal study & $(231)$ \\
\hline miR-49 & Up & PBMC & - & - & (232) \\
\hline miR-326 & Down & PBMC & - & - & (232) \\
\hline miR-34a-5p & Down & ST & XBP1 signaling & Cell culture & (233) \\
\hline miR-20a & Down & FLS & ADAM10 signaling & Cell culture & $(234)$ \\
\hline$m i R-145-5 p$ & Down & FLS & Wnt1/ß-catenin pathway & Cell culture & $(235)$ \\
\hline miR-365 & Down & FLS & IGF1 signaling or PI3K/AKT/mTOR pathway & Animal study & $(236)$ \\
\hline miR-34a & Down & BM-MSC-Evs & cyclin I/ATM/ATR/p53 axis & Cell culture & $(237)$ \\
\hline miR-124a & Down & FLS & PIK3/NF-кB pathway & Cell culture & $(238)$ \\
\hline miR-9-5p & Down & Serum & REST/miR-132 pathway & Cell culture & (239) \\
\hline miR-34a-5p & Down & ST & XBP1 signaling & Cell culture & $(233)$ \\
\hline \multicolumn{6}{|l|}{ IncRNAs } \\
\hline linc01197 & Down & ST & miRNA-150/THBS2 axis & Cell culture & $(240)$ \\
\hline \multirow[t]{4}{*}{ IncRNA NEAT1 } & Up & PBMC- exos & miRNA-23a/MDM2/SIRT6 Axis & Cell culture & $(241)$ \\
\hline & Up & ST, FLS & miR-204-5p signaling & Cell culture & $(242)$ \\
\hline & Up & ST, FLS & MAPK/ERK pathway & Cell culture & $(243)$ \\
\hline & Up & FLS & miR-410-3p/MY1 axis & Cell culture & $(244)$ \\
\hline \multirow[t]{3}{*}{ IncRNA PVT1 } & Up & FLS & miRNA-145-5p & Cell culture & $(245)$ \\
\hline & Up & ST & miR-543-dependent SCUBE2 & Cell culture & $(246)$ \\
\hline & Up & FLS & SIRT6 & Cell culture & $(247)$ \\
\hline IncRNA OIP5-AS1 & Down & FLS & miR-448-PON1/TLR3/NF- $\kappa$ B axis & Cell culture & $(248)$ \\
\hline IncRNA ZFAS1 & Up & FLS & miR-296-5p/MMP-15 & Animal study & $(249)$ \\
\hline
\end{tabular}


TABLE 4 | Continued

\begin{tabular}{|c|c|c|c|c|c|}
\hline NcRNAs & Expression & Tissue & Signalings & Phases & References \\
\hline & Up & FLS & miR-2682-5p/ADAMTS9 axis & Cell culture & $(250)$ \\
\hline linc00152 & Up & FLS & Wnt/ $\beta$-catenin pathway & Cell culture & $(251)$ \\
\hline IncRNA MALAT1 & Down & PBMC & Notch pathway & Cell culture & $(252)$ \\
\hline \multirow[t]{2}{*}{ IncRNA GAS5 } & Down & FLS & miR-128-3p/HDAC4 axis & Cell culture & $(253)$ \\
\hline & Down & ST, FS & HIPK2 signaling & Cell culture & $(254)$ \\
\hline IncRNA HAND2-AS1 & Down & MSC-exos & miR-143-3p/TNFAIP3/NF-кB pathway & Cell culture & $(255)$ \\
\hline IncRNAS56464.1 & Up & FLS & miR-152-3p/Wnt pathway & Cell culture & $(256)$ \\
\hline IncRNA PICSAR & Up & FLS & miRNA-4701-5p signaling & Cell culture & $(257)$ \\
\hline IncRNA MEG3 & Down & FLS & miR-141/AKT/mTOR pathway & Animal study & $(258)$ \\
\hline IncRNA ITSN1-2 & Up & FLS & NOD2/RIP2 pathway & Cell culture & (259) \\
\hline IncAL928768.3 & Up & FLS & - & - & $(260)$ \\
\hline IncAC091493.1 & Up & FLS & - & - & $(260)$ \\
\hline IncRNA HOTTIP & Up & FLS & SFRP1 demethylation & Cell culture & $(261)$ \\
\hline IncRNA HIX003209 & Up & PBMC & TLR4/NF-кB pathway & Cell culture & $(262)$ \\
\hline IncRNA FER1L4 & Down & ST, FLS & NLRC5 signaling & Cell culture & $(263)$ \\
\hline IncRNA CASC2 & Down & Plasma & IL-17 signaling & Cell culture & $(264)$ \\
\hline IncRNA PIncRNA-1 & Down & Serum, SF & TGF- $\beta 1$ signaling & Cell culture & $(265)$ \\
\hline \multirow[t]{2}{*}{ IncRNA H19 } & Up & FLS & Notch pathway & Cell culture & $(266)$ \\
\hline & Up & FLS & $\operatorname{miR}-124 a$ & Animal study & $(267)$ \\
\hline IncRNA RP11-83J16.1 & Down & FLS & $\beta$-catenin pathway & Cell culture & $(268)$ \\
\hline IncRNA H19 & Down & FLS & $\mathrm{NF}-\kappa \mathrm{B}$ and JNK/p38 MAPK pathways & Cell culture & $(269)$ \\
\hline IncRNA XIST & Up & CT & STAT3 signaling & Animal study & $(270)$ \\
\hline IncRNA SNHG1 & Up & FLS & PTBP1 signaling & Cell culture & $(271)$ \\
\hline IncRNA THRIL & Up & Serum & PI3K/AKT pathway & Cell culture & $(272)$ \\
\hline \multicolumn{6}{|l|}{ circRNAs } \\
\hline circ_0088036 & Up & FLS & miR-140-3p/SIRT 1 axis & Cell culture & $(273)$ \\
\hline circ_0000396 & Down & FLS & miR-203/HBP1 axis & Cell culture & $(274)$ \\
\hline circ_AFF2 & Up & FLS & miR-375/TAB2 axis & Cell culture & $(275)$ \\
\hline circ_0130438 & Down & PBMC & - & - & $(276)$ \\
\hline circ_0002715 & Up & PB & - & - & $(277)$ \\
\hline circ_0035197 & Up & PB & - & - & $(277)$ \\
\hline circRNA_09505 & Up & PBMC & miR-6089/AKT1/NF- $к B$ axis & Animal study & $(278)$ \\
\hline circFADS2 & Down & $A C$ & miR-498/mTOR pathway & Cell culture & $(279)$ \\
\hline circ_0000175 & Down & PBMC & - & - & $(280)$ \\
\hline Circ_0008410 & Up & PBMC & - & - & $(280)$ \\
\hline
\end{tabular}

FLS, fibroblast-like synoviocytes; CT, cartilage tissues; AC, articular chondrocytes; ST, synovial tissues; BM-MSC-Evs, bone marrow mesenchymal stem cell -derived extracellular vesicles; MSC-exos, mesenchymal stem cell-derived exosomes; PB, peripheral blood; FoxC1, forkhead box C1; PTGS2, prostaglandin-endoperoxide synthase 2; SOX5, sex determining region Ybox protein 5; CTGF, connective tissue growth factor; SFDE, synovial fibroblast-derived exosomes; PDK4, pyruvate dehydrogenase kinase 4; NF-KB, nuclear factor kappa-B; RANKL, receptor activator of nuclear factor-kb ligand; MDM2, murine double minute-2; SIRT6, sirtuin 6; TLR3, toll-like receptor 3; BMP, bone morphogenetic protein; Smad, mouse signal transduction molecule; MMP-15, matrix metalloproteinase 15; XBP1, X-box binding protein 1; Wnt, wingless and integration-1; ADAM, a disintegrin and metalloprotease 10; SCUBE2, signal peptide-CUB-EGF-like containing protein 2; MAPK, mitogen-activated protein kinase; ERK, extracellular regulated protein kinase; HBP1, HMG-box transcription factor 1; HDAC4, histone deacetylase 4; TNFAIP3, tumor necrosis factor alpha-inducible protein 3; TAB2, TAK1-binding 2; ATM, ataxia-telangiectasia mutated; ATR, ATM-Rad3-related; JAK, janus kinase; STAT, signal transducers and activators of transcription; TLR 5, toll-like receptor 5; DDK1, dickkopf 1; PI3K, phosphatidylinositol 3-kinase; REST, presentational state transfer; PBM, peripheral blood monocytes; FOXO3a, forkhead box O3 alpha; SIRT6, sirtuin 6; HMGB1, high-mobility group box protein 1; C/EBP $\beta$, CCAAT enhancer-binding protein $\beta$; IGF-1R, insulinlike growth factor 1 receptor; HIPK2, homeodomain-interacting protein kinase 2; SOCS 3, suppressors of cytokine signaling 3; NOD2, nucleotide-binding oligomerization domain 2; RIPK2, receptor interacting serine threonine kinase 2; NLRC5, nucleotide oligomerisation domain-like receptors 5; TGF-b1, transforming growth factor beta 1; PTBP1, polypyridine tract-binding protein 1; HIPK2, homeodomain-interacting protein kinase 2; THBS2, thrombospondin 2; PBMC, peripheral blood monouclear cell; exos: exosomes; ADAMTS9, ADAM metallopeptidase with thrombospondin type 1 motif 9; mTOR, mammalian target of rapamycinMammalian target of rapamycin.

mechanisms described above reveal that identification of lncRNA-miRNA interaction provides new insights into the pathogenesis of RA. Thus, lncRNAs are potential and valuable targets for treating RA.

circRNAs are a category of newly endogenous non-coding RNA, and they are becoming significant members of the gene regulation environment, the most representative characteristic of which is the covalently closed RNA circle without $5^{\prime}$ end caps and $3^{\prime}$ poly tails. circRNAs have been reported to involve in the pathogenesis of some autoimmune diseases and have a wide range of functions, such as RNA polymerase (RNAP) II elongation, miRNA and RBP sponge, RNA maturation regulation, protein localization, and so on (290). Also, several
circRNAs might be important targets in clinical blood samples for RA diagnosis, which show a significant association with DAS28, RF, CRP, such as circ0003972 (291), circ0002715 (277).

Several studies reveal the partial and hidden molecular mechanisms of circRNAs in the pathogenesis of RA. circ0088036 is found to be aberrantly upregulated in RA FLS, and it facilitates RA progression by acting as a miR-140-3p sponge to upregulate SIRT 1 expression (273). circFADS2 protects chondrocytes from apoptosis by acting as an interceptor in miR-498/mTOR singling pathway (292). circ_0000396 regulates miR-203/HBP1 axis to inhibit the growth of RA FLS (274). Besides, circRNA_09505 can promote AKT1 expression via regulating the $\mathrm{I} \kappa \mathrm{B} \alpha / \mathrm{NF}-\kappa \mathrm{B}$ signaling 
pathway in macrophages, the most interesting is circRNA_09505 knockdown significantly alleviates arthritis and inflammation in CIA mice (278). These emerging studies elucidate that circRNAs are potential and promising targets for RA therapy. In the future, more mechanisms of circRNAs in RA need to be uncovered.

\section{DNA Methylation}

Methylation of DNA is carried out by the activity of DNA methyltransferases (DNMT) and leads to the formation of 5methylcytosine (5-mC), which further affect various life activities. Altered DNA methylation patterns have been identified in clinical RA. In RA patients, an alteration of DNA methylome signature in $\mathrm{PBMC}$ and a reduction of $5-\mathrm{mC}$ amounts in synovial tissues were observed, the alteration of FLS gene expression, including chitinase-3-like protein 1 (CHI3L1), caspase 1 (CASP1), STAT3, mitogen-activated protein kinase kinase kinase 5 (MAP3K5), familial Mediterranean fever (MEFV), and wnt1-inducible signaling protein 3 (WISP3), is caused by differentially methylated genes leading to the pathogenesis of RA (293). In addition, the change of DNA methylation is rather different between early and late stage $(294,295)$. Studies have shown that several DNMT inhibitors including azacitidine, decitabine, procainamide, hydralazine, and epigallocatechin-3-gallate are applied in animals, which show excellent efficacies via decreasing proinflammatory cytokines (i.e., IL-6, TNF- $\alpha$, and TGF) (177).

\section{RNA Methylation}

The most common methylated modification of RNA is N6methyladenosine (m6A). m6A methyltransferase, m6A demethylase, and m6A RNA-binding protein are essential for m6A RNA modification $(296,297)$. It is reported that WTAP, RIPK2, JAK3, and TNFRSF10A genes identified by transcriptome-wide high-throughput m6A sequencing are in accordance with $\mathrm{m6A}$, which are increased in inflammationrelated pathways, cell proliferation, and apoptosis in FLS (298). In the RA patient's peripheral blood, m6A demethylases (ALKBH5 and FTO) and m6A RNA-binding protein (YTHDF2) are proven to have an association with DAS28, complement 3 (C3), and immunoglobulin G (IgG) (297). As a key methyltransferase of m6A, METTL3 can inhibit the activation of pTHP-1 macrophages by preventing the generation of IL- 6 and TNF- $\alpha$, and attenuate inflammatory response induced by LPS via the NF- $\kappa B$ signaling pathway (178). These studies provide novel prospects for us in recognizing the pathogenesis of RA and finding promising targets for RA.

\section{Histone Modifications}

The histones can be modified in many ways posttranslationally, including acetylation, methylation, citrullination, ubiquitination, phosphorylation, and sumoylation (299, 300). These modifications implicate RA occurrence.

\section{Histone Acetylation}

For histone acetylation, most studies mainly focus on histone acetyltransferase (HAT) and histone deacetylases (HDAC).
There are four types of HDAC, including class I (HDAC1-3, HDAC8), class II (HDAC4-7, HDAC9-10), class III (SIRT1-7), and class IV (HDAC11) (183). It has been reported that HDAC activity is involved in RA synovial are significantly increased compared with normal controls and are in direct proportion to TNF- $\alpha$ mRNA levels (301). In contrast, inflammatory stimuli diminish the expression of HDAC5 to regulate the generation of cytokines and chemokines through modulation of IRF1 in RA FLS (302). In addition, the mRNA and protein levels of SIRT1 in RA LFS are lower than normal FLS, and increased SIRT1 expression strikingly suppresses the invasiveness of RA FLS by inhibiting MMP1 and MMP13 expression (303). An animal study also shows that knockout specifically of SIRT1 in myeloid cells alleviates synovial inflammation and bone destruction of RA by decreasing Th1 and Th17 differentiation (304).

Two inhibitors of histone acetyltransferase (delphinidin and anacardic acid) suppress FLS proliferation and invasion, which further ameliorates inflammatory $(179,180)$. In addition, many HDAC inhibitors aiming at different HDAC types are also shown to suppress inflammation in cell or animal experiments, entinostat, MI192, trichostatin A, and valproic acid (Table 2). These experiment results display potent therapeutic efficacies of HDAC inhibitors in RA remission (186, 305). Moreover, bromodomain and extra-terminal (BET) family proteins can identify acetylated histones. I-BET151 (a selective inhibitor of $\mathrm{BET}$ ) can reduce joint inflammation and bone loss by blocking MMP-1, MMP-3, IL-6, and IL-8 production in RA FLS (190, 306). Similar results are seen with another BET inhibitor, JQ1, suggesting that this family of proteins may be promising therapeutic targets (191).

\section{Other Histone Modifications}

The involvement of histone methylation is important in the pathogenesis of RA. H3K4me3 in SF is associated with the onset of arthritis-activated chromatin. GSK-J4 can inhibit the H3K27me3 methylation at the TLR2 promoter, which significantly relieves the articular cartilage destruction and inflammation (307). The histone methyltransferase enhancer of zeste homolog 2 (EZH2) is discovered to overexpress in RA FLS and can be induced by TNF- $\alpha$ through the JAK and NF- $\kappa B$ pathways. EZH2-mediated epigenetic alteration of secreted frizzled-related protein 1 (SFRP1) significantly correlates with the activation of RA FLS (308).

\section{CONCLUSION AND PERSPECTIVE}

RA is an autoimmune disease with complex etiology. To date, under unremitting efforts, RA has been altered from a highly disabling disease without effective treatment to a disease that can be well controlled. Many patients achieve remission or low disease state, which can be attributed to the development of specific DMARDs. However, the main problems of marketed biologics/drugs are nonresponses and partial responses as well as the occurrence of adverse effects like stomatitis, exanthema, and diarrhea. This review summarizes new targets, including 
proteins, small molecular metabolites, and epigenetics regulators. They are promising molecular targets for drug discovery to alleviate the onset of diseases and solve nonresponses and partial responses as well as adverse effects for current DMARDs.

It is undeniable that greater efforts are still needed to more accurately define the underlying signaling pathways affected by these newly discovered molecules and to develop appropriate therapy methods. Extensive pre-clinic studies and clinical trials also are required for proving the druggable potential of these targets. With the great success of biologic drugs targeting TNF, it seems that cytokines (i.e., IL-1 $\beta$, IL-6, and IL-7) and chemokines (i.e., CXCL1, CCR2, and CX3CL1) could be more potent molecular targets when compared to intracellular protein targets (i.e., p38MAPK, ERK, and JNK). However, some cutting-edge technologies like PROTACs (proteolysis-targeting chimeras), RNA interference, clustered regularly interspaced short palindromic repeats (CRISPR)/Cas9-based genome editing, and artificial intelligence (AI)-based drug design, allow screening of therapeutics targeting almost all kinds of molecules, like proteins and epigenetic regulators. For example, PROTACs could be used to degrade intracellular signal transducers or undruggable protein molecules. IncRNAs or miRNAs could be manipulated by small interfering RNAs, antisense RNAs, RNA mimics, or CRISPR/Cas9 carried by nanoparticle-based delivery systems. There are also inhibitors targeting methylation, acetylation, or other epigenetic modifications, which may have promising potential for RA treatment.

At present, different medication combinations are common strategies to relieve the pain and joint inflammation of RA patients. Because of the high heterogeneity of RA, researchers realize that the current efforts are far from enough to recommend

\section{REFERENCES}

1. Smolen JS, Aletaha D, Barton A, Burmester GR, Emery P, Firestein GS, et al. Rheumatoid Arthritis. Nat Rev Dis Primers (2018) 4:18001. doi: 10.1038/ nrdp.2018.1

2. Szekanecz Z, Koch AE, Tak PP. Chemokine and Chemokine Receptor Blockade in Arthritis, a Prototype of Immune-Mediated Inflammatory Diseases. Netherlands J Med (2011) 69(9):356-66.

3. Firestein GS. Evolving Concepts of Rheumatoid Arthritis. Nature (2003) 423 (6937):356-61. doi: 10.1038/nature01661

4. Ngo ST, Steyn FJ, McCombe PA. Gender Differences in Autoimmune Disease. Front Neuroendocrinol (2014) 35(3):347-69. doi: 10.1016/ j.yfrne.2014.04.004

5. Turesson C, O'Fallon WM, Crowson CS, Gabriel SE, Matteson EL. ExtraArticular Disease Manifestations in Rheumatoid Arthritis: Incidence Trends and Risk Factors Over 46 Years. Ann Rheum Dis (2003) 62(8):722-7. doi: 10.1136/ard.62.8.722

6. Crofford LJ. Use of NSAIDs in Treating Patients With Arthritis. Arthritis Res Ther (2013) 15(Suppl 3):S2-S. doi: 10.1186/ar4174

7. Bullock J, Rizvi SAA, Saleh AM, Ahmed SS, Do DP, Ansari RA, et al. Rheumatoid Arthritis: A Brief Overview of the Treatment. Med Princ Pract (2018) 27(6):501-7. doi: 10.1159/000493390

8. Lamers-Karnebeek FBG, Jacobs JWG, Radstake TRDJ, van Riel P, Jansen TL. Adalimumab Drug and Antidrug Antibody Levels do Not Predict Flare Risk After Stopping Adalimumab in RA Patients With Low Disease Activity. Rheumatology (2019) 58(3):427-31. doi: 10.1093/rheumatology/key292

9. Leake I. Tocilizumab or TNF Inhibitors in RA? Nat Rev Rheumatol (2018) 14(7):384. doi: 10.1038/s41584-018-0031-7 specific DMARDs for individual patients. Precision medicine is an emerging medical model that considers the genetics, environment, and lifestyle of patients to select the treatment that could work best for them. Future studies could separate RA patients into subgroups and establish precision medicine strategies to realize personalized therapy.

\section{AUTHOR CONTRIBUTIONS}

$\mathrm{CL}$ designed and supervised the manuscript. $\mathrm{JH}$ and $\mathrm{XF}$ consulted literatures and wrote the manuscript in equal contribution. $\mathrm{ZL}, \mathrm{XC}$, and $\mathrm{YH}$ proposed advice to the manuscript. All authors contributed to the article and approved the submitted version.

\section{FUNDING}

This work was supported by the Natural Science Foundation Council of China (81922081and 81700780).

\section{ACKNOWLEDGMENTS}

We thank the administrative assistant (Ms. Yufang Zuo) for providing help and support. Figures 1-3 were modified from Servier Medical Art (http://smart.servier.com/), licensed under a Creative Common Attribution 4.0 Generic License. (https:// creativecommons.org/licenses/by/4.0/).

10. Rice C, Ghandi-Das D, Negi A. Monitoring of Immunoglobulin Levels in RA Patients on Anti CD20, Rituximab. Rheumatology (2020) 59Supplement_2:94. doi: 10.1093/rheumatology/keaa111.197

11. Ho CTK, Mok CC, Cheung TT, Kwok KY, Yip RML. Management of Rheumatoid Arthritis: 2019 Updated Consensus Recommendations From the Hong Kong Society of Rheumatology. Clin Rheumatol (2019) 38 (12):3331-50. doi: 10.1007/s10067-019-04761-5

12. Mittal N, Mittal R, Sharma A, Jose V, Wanchu A, Singh S. Treatment Failure With Disease-Modifying Antirheumatic Drugs in Rheumatoid Arthritis Patients. Singapore Med J (2012) 53(8):532-6.

13. Santos-Moreno PI, de la Hoz-Valle J, Villarreal L, Palomino A, Sanchez G, Castro C. Treatment of Rheumatoid Arthritis With Methotrexate Alone and in Combination With Other Conventional DMARDs Using the T2T Strategy. A Cohort Study. Clin Rheumatol (2015) 34(2):215-20. doi: 10.1007/s10067-014-2794-9

14. Nadarajah N, Pramudyo R. Kuswinarti. Treatment of Rheumatoid Arthritis With Methotrexate Alone or A Combination of Methotrexate and Hydroxychloroquine. Althea Med J (2016) 3(3):446-51. doi: 10.15850/amj.v3n3.474

15. Smolen JS, Landewé RBM, Bijlsma JWJ, Burmester GR, Dougados M, Kerschbaumer A, et al. EULAR Recommendations for the Management of Rheumatoid Arthritis With Synthetic and Biological Disease-Modifying Antirheumatic Drugs: 2019 Update. Ann Rheum Dis (2020) 79(6):685-99. doi: 10.1136/annrheumdis-2019-216655

16. Sotoudehmanesh R, Anvari B, Akhlaghi M, Shahraeeni S, Kolahdoozan S. Methotrexate Hepatotoxicity in Patients With Rheumatoid Arthritis. Middle East J Dig Dis (2010) 2(2):104-9.

17. Bonbardier C, Laine L, Reicin A, Shapiro D, Burgos-Vargas R, Davis B. Comparison of Upper Gastrointestinal Toxicity of Rofecoxib and Naproxen 
in Patients With Rheumatoid Arthritis. N Engl J Med (2000) 343(21):1520-8. doi: 10.1056/NEJM200011233432103

18. Gautam R, Singh M, Gautam S, Rawat JK, Saraf SA, Kaithwas G. Rutin Attenuates Intestinal Toxicity Induced by Methotrexate Linked With AntiOxidative and Anti-Inflammatory Effects. BMC Complement Altern Med (2016) 16(1):99. doi: 10.1186/s12906-016-1069-1

19. Choy E. Understanding the Dynamics: Pathways Involved in the Pathogenesis of Rheumatoid Arthritis. Rheumatololy (Oxford) (2012) 51 (Suppl 5):v3-11. doi: 10.1093/rheumatology/kes113

20. Cheng Q, Wu H, Du Y. The Roles of Small-Molecule Inflammatory Mediators in Rheumatoid Arthritis. Scand J Immunol (2021) 93(3):e12982. doi: $10.1111 /$ sji.12982

21. Klein K, Gay S. Epigenetics in Rheumatoid Arthritis. Curr Opin Rheumatol (2015) 27(1):76-82. doi: 10.1097/BOR.0000000000000128

22. Galeazzi M, Sebastiani G, Voll R, Viapiana O, Dudler J, Zufferey P, et al. FRI0118 Dekavil (F8IL10) - Update on the Results of Clinical Trials Investigating the Immunocytokine in Patients With Rheumatoid Arthritis. J Ann Rheumatic Dis (2018) 77(Suppl 2):603-4. doi: 10.1136/annrheumdis2018-eular.5550

23. Baslund B, Tvede N, Danneskiold-Samsoe B, Larsson P, Panayi G, Petersen J, et al. Targeting Interleukin-15 in Patients With Rheumatoid Arthritis: A Proofof-Concept Study. Arthritis Rheum (2005) 52(9):2686-92. doi: 10.1002/ art. 21249

24. Tak PP, Bacchi M, Bertolino M. Pharmacokinetics of IL-18 Binding Protein in Healthy Volunteers and Subjects With Rheumatoid Arthritis or Plaque Psoriasis. Eur J Drug Metab Pharmacokinet (2006) 31(2):109-16. doi: $10.1007 /$ bf03191127

25. Yellin M, Paliienko I, Balanescu A, Ter-Vartanian S, Tseluyko V, Xu LA, et al. A Phase II, Randomized, Double-Blind, Placebo-Controlled Study Evaluating the Efficacy and Safety of MDX-1100, a Fully Human AntiCXCL10 Monoclonal Antibody, in Combination With Methotrexate in Patients With Rheumatoid Arthritis. Arthritis Rheum (2012) 64(6):1730-9. doi: $10.1002 /$ art. 34330

26. Webber J, Stone TC, Katilius E, Smith BC, Gordon B, Mason MD, et al. Proteomics Analysis of Cancer Exosomes Using a Novel Modified AptamerBased Array (SOMAscan ${ }^{\mathrm{TM}}$ ) Platform. Mol Cell Proteom: MCP (2014) 13 (4):1050-64. doi: 10.1074/mcp.M113.032136

27. Shahrara S, Proudfoot AE, Park CC, Volin MV, Haines GK, Woods JM, et al. Inhibition of Monocyte Chemoattractant Protein-1 Ameliorates Rat Adjuvant-Induced Arthritis. J Immunol (Baltimore Md: 1950) (2008) 180 (5):3447-56. doi: 10.4049/jimmunol.180.5.3447

28. Haringman JJ, Gerlag DM, Smeets TJ, Baeten D, van den Bosch F, Bresnihan B, et al. A Randomized Controlled Trial With an Anti-CCL2 (Anti-Monocyte Chemotactic Protein 1) Monoclonal Antibody in Patients With Rheumatoid Arthritis. Arthritis Rheum (2006) 54(8):2387-92. doi: 10.1002/art.21975

29. Ruth JH, Park CC, Amin MA, Lesch C, Marotte H, Shahrara S, et al. Interleukin-18 as an In Vivo Mediator of Monocyte Recruitment in Rodent Models of Rheumatoid Arthritis. Arthritis Res Ther (2010) 12(3):R118-R. doi: 10.1186/ar3055

30. Tanaka Y, Takeuchi T, Yamanaka H, Nanki T, Umehara H, Yasuda N, et al. A Phase 2 Study of E6011, an Anti-Fractalkine Monoclonal Antibody, in Patients With Rheumatoid Arthritis Inadequately Responding to Biological Disease-Modifying Antirheumatic Drugs. Modern Rheumatol (2021) 31 (4):783-9. doi: 10.1080/14397595.2020.1868675

31. Liu X, Ni S, Li C, Xu N, Chen W, Wu M, et al. Circulating microRNA-23b as a New Biomarker for Rheumatoid Arthritis. Gene (2019) 712:143911-. doi: 10.1016/j.gene.2019.06.001

32. Lebre MC, Vergunst CE, Choi IY, Aarrass S, Oliveira AS, Wyant T, et al. Why CCR2 and CCR5 Blockade Failed and Why CCR1 Blockade Might Still be Effective in the Treatment of Rheumatoid Arthritis. PloS One (2011) 6(7): e21772. doi: 10.1371/journal.pone.0021772

33. Tak PP, Balanescu A, Tseluyko V, Bojin S, Drescher E, Dairaghi D, et al. Chemokine Receptor CCR1 Antagonist CCX354-C Treatment for Rheumatoid Arthritis: CARAT-2, a Randomised, Placebo Controlled Clinical Trial. Ann Rheum Dis (2013) 72(3):337-44. doi: 10.1136/annrheumdis-2011-201605

34. Lenert A, Fardo DW. Detecting Novel Micro RNAs in Rheumatoid Arthritis With Gene-Based Association Testing. Clin Exp Rheumatol (2017) 35 (4):586-92.
35. Vergunst CE, Gerlag DM, Lopatinskaya L, Klareskog L, Smith MD, van den Bosch F, et al. Modulation of CCR2 in Rheumatoid Arthritis: A DoubleBlind, Randomized, Placebo-Controlled Clinical Trial. Arthritis Rheum (2008) 58(7):1931-9. doi: 10.1002/art.23591

36. Shahrara S, Proudfoot AE, Woods JM, Ruth JH, Amin MA, Park CC, et al. Amelioration of Rat Adjuvant-Induced Arthritis by Met-RANTES. Arthritis Rheum (2005) 52(6):1907-19. doi: 10.1002/art.21033

37. Gerlag DM, Hollis S, Layton M, Vencovský J, Szekanecz Z, Braddock M, et al. Preclinical and Clinical Investigation of a CCR5 Antagonist, AZD5672, in Patients With Rheumatoid Arthritis Receiving Methotrexate. Arthritis Rheum (2010) 62(11):3154-60. doi: 10.1002/art.27652

38. Fleishaker DL, Garcia Meijide JA, Petrov A, Kohen MD, Wang X, Menon S, et al. Maraviroc, a Chemokine Receptor-5 Antagonist, Fails to Demonstrate Efficacy in the Treatment of Patients With Rheumatoid Arthritis in a Randomized, Double-Blind Placebo-Controlled Trial. Arthritis Res Ther (2012) 14(1):R11. doi: 10.1186/ar3685

39. van Kuijk AW, Vergunst CE, Gerlag DM, Bresnihan B, Gomez-Reino JJ, Rouzier R, et al. CCR5 Blockade in Rheumatoid Arthritis: A Randomised, Double-Blind, Placebo-Controlled Clinical Trial. Ann Rheum Dis (2010) 69 (11):2013-6. doi: 10.1136/ard.2010.131235

40. Gossage DL, Cieslarová B, Ap S, Zheng H, Xin Y, Lal P, et al. Phase 1b Study of the Safety, Pharmacokinetics, and Disease-Related Outcomes of the Matrix Metalloproteinase-9 Inhibitor Andecaliximab in Patients With Rheumatoid Arthritis. Clin Ther (2018) 40(1):156-65.e5. doi: 10.1016/ j.clinthera.2017.11.011

41. Kuhn C, Weiner HL. Therapeutic Anti-CD3 Monoclonal Antibodies: From Bench to Bedside. Immunotherapy (2016) 8(8):889-906. doi: 10.2217/imt2016-0049

42. Emery P, Burmester GR, Bykerk VP, Combe BG, Furst DE, Barré E, et al. Evaluating Drug-Free Remission With Abatacept in Early Rheumatoid Arthritis: Results From the Phase 3b, Multicentre, Randomised, ActiveControlled AVERT Study of 24 Months, With a 12-Month, Double-Blind Treatment Period. Ann Rheum Dis (2015) 74(1):19-26. doi: 10.1136/ annrheumdis-2014-206106

43. Schafer PH, Kivitz AJ, Ma J, Korish S, Sutherland D, Li L, et al. Spebrutinib (CC-292) Affects Markers of B Cell Activation, Chemotaxis, and Osteoclasts in Patients With Rheumatoid Arthritis: Results From a Mechanistic Study. Rheumatol Ther (2020) 7(1):101-19. doi: 10.1007/s40744-019-00182-7

44. Krausz S, Boumans MJ, Gerlag DM, Lufkin J, van Kuijk AW, Bakker A, et al. Brief Report: A Phase IIa, Randomized, Double-Blind, Placebo-Controlled Trial of Apilimod Mesylate, an Interleukin-12/Interleukin-23 Inhibitor, in Patients With Rheumatoid Arthritis. Arthritis Rheum (2012) 64(6):1750-5. doi: 10.1002/art.34339

45. Crotti C, Agape E, Becciolini A, Biggioggero M, Favalli EG. Targeting Granulocyte-Monocyte Colony-Stimulating Factor Signaling in Rheumatoid Arthritis: Future Prospects. Drugs (2019) 79(16):1741-55. doi: 10.1007/s40265-019-01192-z

46. Dufton N, Hannon R, Brancaleone V, Dalli J, Patel HB, Gray M, et al. AntiInflammatory Role of the Murine Formyl-Peptide Receptor 2: LigandSpecific Effects on Leukocyte Responses and Experimental Inflammation. J Immunol (Baltimore Md: 1950) (2010) 184(5):2611-9. doi: 10.4049/ jimmunol.0903526

47. Dakin SG, Colas RA, Wheway K, Watkins B, Appleton L, Rees J, et al. Proresolving Mediators LXB4 and RvE1 Regulate Inflammation in Stromal Cells From Patients With Shoulder Tendon Tears. Am J Pathol (2019) 189 (11):2258-68. doi: 10.1016/j.ajpath.2019.07.011

48. Nanki T, Shimaoka T, Hayashida K, Taniguchi K, Yonehara S, Miyasaka N. Pathogenic Role of the CXCL16-CXCR6 Pathway in Rheumatoid Arthritis. Arthritis Rheum (2005) 52(10):3004-14. doi: 10.1002/art.21301

49. Grespan R, Fukada SY, Lemos HP, Vieira SM, Napimoga MH, Teixeira MM, et al. CXCR2-Specific Chemokines Mediate Leukotriene B4-Dependent Recruitment of Neutrophils to Inflamed Joints in Mice With AntigenInduced Arthritis. Arthritis Rheum (2008) 58(7):2030-40. doi: 10.1002/ art.23597

50. Barsante MM, Cunha TM, Allegretti M, Cattani F, Policani F, Bizzarri C, et al. Blockade of the Chemokine Receptor CXCR2 Ameliorates AdjuvantInduced Arthritis in Rats. Br J Pharmacol (2008) 153(5):992-1002. doi: $10.1038 /$ sj.bjp. 0707462 
51. Jenh CH, Cox MA, Cui L, Reich EP, Sullivan L, Chen SC, et al. A Selective and Potent CXCR3 Antagonist SCH 546738 Attenuates the Development of Autoimmune Diseases and Delays Graft Rejection. BMC Immunol (2012) 13:2. doi: 10.1186/1471-2172-13-2

52. Bakheet SA, Ansari MA, Nadeem A, Attia SM, Alhoshani AR, Gul G, et al. CXCR3 Antagonist AMG487 Suppresses Rheumatoid Arthritis Pathogenesis and Progression by Shifting the Th17/Treg Cell Balance. Cell Signal (2019) 64:109395. doi: 10.1016/j.cellsig.2019.109395

53. Kim B, Lee JH, Jin WJ, Kim HH, Ha H, Lee ZH. JN-2, a C-X-C Motif Chemokine Receptor 3 Antagonist, Ameliorates Arthritis Progression in an Animal Model. Eur J Pharmacol (2018) 823:1-10. doi: 10.1016/j.ejphar. 2018.01.037

54. Matthys P, Hatse S, Vermeire K, Wuyts A, Bridger G, Henson GW, et al. AMD3100, a Potent and Specific Antagonist of the Stromal Cell-Derived Factor-1 Chemokine Receptor CXCR4, Inhibits Autoimmune Joint Inflammation in IFN-Gamma Receptor-Deficient Mice. J Immunol (Baltimore Md: 1950) (2001) 167(8):4686-92. doi: 10.4049/jimmunol. 167.8.4686

55. Tamamura H, Fujisawa M, Hiramatsu K, Mizumoto M, Nakashima H, Yamamoto N, et al. Identification of a CXCR4 Antagonist, a T140 Analog, as an Anti-Rheumatoid Arthritis Agent. FEBS Lett (2004) 569(1-3):99-104. doi: 10.1016/j.febslet.2004.05.056

56. Watanabe K, Penfold ME, Matsuda A, Ohyanagi N, Kaneko K, Miyabe Y, et al. Pathogenic Role of CXCR7 in Rheumatoid Arthritis. Arthritis Rheum (2010) 62(11):3211-20. doi: 10.1002/art.27650

57. Moschovakis GL, Bubke A, Friedrichsen M, Ristenpart J, Back JW, Falk CS, et al. The Chemokine Receptor CCR7 Is a Promising Target for Rheumatoid Arthritis Therapy. Cell Mol Immunol (2019) 16(10):791-9. doi: 10.1038/ s41423-018-0056-5

58. Harrington R, Al Nokhatha SA, Conway R. JAK Inhibitors in Rheumatoid Arthritis: An Evidence-Based Review on the Emerging Clinical Data. J Inflammation Res (2020) 13:519-31. doi: 10.2147/jir.S219586

59. Wiese MD, Manning-Bennett AT, Abuhelwa AY. Investigational IRAK-4 Inhibitors for the Treatment of Rheumatoid Arthritis. Expert Opin Investig Drugs (2020) 29(5):475-82. doi: 10.1080/13543784.2020.1752660

60. van de Veerdonk FL, Lauwerys B, Marijnissen RJ, Timmermans K, Di Padova F, Koenders MI, et al. The Anti-CD20 Antibody Rituximab Reduces the Th17 Cell Response. Arthritis Rheum (2011) 63(6):1507-16. doi: $10.1002 /$ art.30314

61. Radner H, Aletaha D. Anti-TNF in Rheumatoid Arthritis: An Overview. Wiener Medizinische Wochenschrift (2015) 165(1):3-9. doi: 10.1007/s10354015-0344-y

62. Dinarello CA. Historical Insights Into Cytokines. Eur J Immunol (2010) 37 (1):S34-45. doi: 10.1002/eji.200737772

63. Goëb V, Aegerter P, Parmar R, Fardellone P, Vittecoq O, Conaghan PG, et al. Progression to Rheumatoid Arthritis in Early Inflammatory Arthritis Is Associated With Low IL-7 Serum Levels. Ann Rheumatic Dis (2013) 72 (6):1032. doi: 10.1136/annrheumdis-2012-202377

64. Guo Y-Y, Wang N-Z, Zhao S, Hou L-X, Xu Y-B, Zhang N. Increased Interleukin-23 is Associated With Increased Disease Activity in Patients With Rheumatoid Arthritis. Chin Med J (2013) 126:850-4. doi: 10.3760/ cma.j.issn.0366-6999.20113093

65. Gullick NJ, Abozaid HS, Jayaraj DM, Evans HG, Scott DL, Choy EH, et al. Enhanced and Persistent Levels of Interleukin (IL)- $17^{+} \mathrm{CD} 4^{+} \mathrm{T}$ Cells and Serum IL-17 in Patients With Early Inflammatory Arthritis. Clin Exp Immunol (2013) 174(2):292-301. doi: 10.1111/cei.12167

66. Reyes-Pérez IV, Sánchez-Hernández PE, Muñoz-Valle JF, Martínez-Bonilla GE, García-Iglesias T, González-Díaz V, et al. Cytokines (IL-15, IL-21, and IFN- $\gamma$ ) in Rheumatoid Arthritis: Association With Positivity to Autoantibodies (RF, AntiCCP, Anti-MCV, and Anti-PADI4) and Clinical Activity. Clin Rheumatol (2019) 38(11):3061-71. doi: 10.1007/s10067-019-04681-4

67. Cook AD, Louis C, Robinson MJ, Saleh R, Sleeman MA, Hamilton JA. Granulocyte Macrophage Colony-Stimulating Factor Receptor $\alpha$ Expression and its Targeting in Antigen-Induced Arthritis and Inflammation. Arthritis Res Ther (2016) 18(1):287. doi: 10.1186/s13075-016-1185-9

68. Kurowska W, Przygodzka M, Jakubaszek M, Kwiatkowska B, Maslinski W. Interleukin-15 as a Biomarker Candidate of Rheumatoid Arthritis Development. J Clin Med (2020) 9(5):1555. doi: 10.3390/jcm9051555
69. Santos Savio A, Machado Diaz AC, Chico Capote A, Miranda Navarro J, Rodríguez Alvarez Y, Bringas Pérez R, et al. Differential Expression of ProInflammatory Cytokines IL-15ralpha, IL-15, IL-6 and TNFalpha in Synovial Fluid From Rheumatoid Arthritis Patients. BMC Musculoskeletal Disord (2015) 16:51. doi: 10.1186/s12891-015-0516-3

70. Lee A, Qiao Y, Grigoriev G, Chen J, Park-Min KH, Park SH, et al. Tumor Necrosis Factor Alpha Induces Sustained Signaling and a Prolonged and Unremitting Inflammatory Response in Rheumatoid Arthritis Synovial Fibroblasts. Arthritis Rheum (2013) 65(4):928-38. doi: 10.1002/art.37853

71. Gao B, Calhoun K, Fang D. The Proinflammatory Cytokines IL-1 $\beta$ and TNF- $\alpha$ Induce the Expression of Synoviolin, an E3 Ubiquitin Ligase, in Mouse Synovial Fibroblasts via the Erk1/2-ETS1 Pathway. Arthritis Res Ther (2006) 8(6):R172. doi: 10.1186/ar2081

72. Mease PJ. Adalimumab in the Treatment of Arthritis. Ther Clin Risk Manag (2007) 3(1):133-48. doi: 10.2147/tcrm.2007.3.1.133

73. Yang CM, Luo SF, Hsieh HL, Chi PL, Lin CC, Wu CC, et al. Interleukin1beta Induces ICAM-1 Expression Enhancing Leukocyte Adhesion in Human Rheumatoid Arthritis Synovial Fibroblasts: Involvement of ERK, JNK, AP-1, and NF-kappaB. J Cell Physiol (2010) 224(2):516-26. doi: $10.1002 /$ jcp. 22153

74. Vincenti MP, Coon CI, Brinckerhoff CE. Nuclear Factor kb/P50 Activates an Element in the Distal Matrix Metalloproteinase 1 Promoter in Interleukin-1 $\beta$ Stimulated Synovial Fibroblasts. Arthritis Rheuma (1998) 41(11):1987-94. doi: 10.1002/1529-0131(199811)41:11<1987::AID-ART14>3.0.CO;2-8

75. Oelzner P, Franke S, Lehmann G, Eidner T, Hein G, Wolf G. The Balance Between Soluble Receptors Regulating IL-6 Trans-Signaling Is Predictive for the RANKL/osteoprotegerin Ratio in Postmenopausal Women With Rheumatoid Arthritis. Rheumatol Int (2012) 32(1):199-206. doi: 10.1007/ s00296-010-1606-Z

76. Little CB, Barai A, Burkhardt D, Smith SM, Fosang AJ, Werb Z, et al. Matrix Metalloproteinase 13-Deficient Mice Are Resistant to Osteoarthritic Cartilage Erosion But Not Chondrocyte Hypertrophy or Osteophyte Development. Arthritis Rheum (2014) 60(12):3723-33. doi: 10.1002/ art. 25002

77. Hartgring SAY, Willis CR, Alcorn D, Nelson LJ, Bijlsma JWJ, Lafeber FPJG, et al. Blockade of the Interleukin-7 Receptor Inhibits Collagen-Induced Arthritis and Is Associated With Reduction of T Cell Activity and Proinflammatory Mediators. Arthritis Rheumatism (2010) 62(9):2716-25. doi: 10.1002/art.27578

78. Rückert R, Brandt K, Ernst M, Marienfeld K, Csernok E, Metzler C, et al. Interleukin-15 Stimulates Macrophages to Activate CD4+ T Cells: A Role in the Pathogenesis of Rheumatoid Arthritis? Immunology (2009) 126(1):6373. doi: $10.1111 / j .1365-2567.2008 .02878 . x$

79. Leung BP, McInnes IB, Esfandiari E, Wei XQ, Liew FY. Combined Effects of IL-12 and IL-18 on the Induction of Collagen-Induced Arthritis. J Immunol (Baltimore Md: 1950) (2000) 164(12):6495-502. doi: 10.4049/ jimmunol.164.12.6495

80. Bouchareychas L, Grössinger EM, Kang M, Qiu H, Adamopoulos IE. Critical Role of LTB4/BLT1 in IL-23-Induced Synovial Inflammation and Osteoclastogenesis via NF-kb. J Immunol (Baltimore Md: 1950) (2017) 198(1):452-60. doi: 10.4049/jimmunol.1601346

81. Ganesan R, Rasool M. Interleukin 17 Regulates SHP-2 and IL-17ra/STAT-3 Dependent Cyr61, IL-23 and GM-CSF Expression and RANKL Mediated Osteoclastogenesis by Fibroblast-Like Synoviocytes in Rheumatoid Arthritis. Mol Immunol (2017) 91:134-44. doi: 10.1016/j.molimm.2017.09.003

82. $\mathrm{Ma} \mathrm{H}, \mathrm{Xu} \mathrm{M}$, Song $\mathrm{Y}$, Zhang $\mathrm{T}$, Yin $\mathrm{H}$, Yin S. Interferon- $\gamma$ Facilitated Adjuvant-Induced Arthritis at Early Stage. Scand J Immunol (2019) 89(5): e12757. doi: $10.1111 /$ sji.12757

83. Qu CH, Hou Y, Bi YF, Han QR, Jiao CH, Zou QF. Diagnostic Values of Serum IL-10 and IL-17 in Rheumatoid Arthritis and Their Correlation With Serum 14-3-3ך Protein. Eur Rev Med Pharmacol Sci (2019) 23(5):1899-906. doi: 10.26355/eurrev_201903_17227

84. Raza K, Falciani F, Curnow SJ, Ross EJ, Lee C-Y, Akbar AN, et al. Early Rheumatoid Arthritis is Characterized by a Distinct and Transient Synovial Fluid Cytokine Profile of T Cell and Stromal Cell Origin. Arthritis Res Ther (2005) 7(4):R784. doi: 10.1186/ar1733

85. Brzustewicz E, Bryl E. The Role of Cytokines in the Pathogenesis of Rheumatoid Arthritis-Practical and Potential Application of Cytokines as 
Biomarkers and Targets of Personalized Therapy. Cytokine (2015) 76 (2):527-36. doi: 10.1016/j.cyto.2015.08.260

86. Eliçabe RJ, Silva JE, Dave MN, Lacoste MG, Tamashiro H, Blas R, et al. Association Between IL-17 and IgA in the Joints of Patients With Inflammatory Arthropathies. BMC Immunol (2017) 18(1):8. doi: 10.1186/ s12865-017-0189-9

87. Zhou G, Sun X, Qin Q, Lv J, Cai Y, Wang M, et al. Loss of Smad7 Promotes Inflammation in Rheumatoid Arthritis. Front Immunol (2018) 9:2537. doi: 10.3389/fimmu.2018.02537

88. Hong KH, Cho ML, Min SY, Shin YJ, Yoo SA, Choi JJ, et al. Effect of Interleukin-4 on Vascular Endothelial Growth Factor Production in Rheumatoid Synovial Fibroblasts. Clin Exp Immunol (2007) 147(3):573-9. doi: 10.1111/j.1365-2249.2006.03295.x

89. Heo YJ, Joo YB, Oh HJ, Park MK, Heo YM, Cho ML, et al. IL-10 Suppresses Th17 Cells and Promotes Regulatory T Cells in the CD4+ T Cell Population of Rheumatoid Arthritis Patients. Immunol Lett (2010) 127(2):150-6. doi: $10.1016 /$ j.imlet.2009.10.006

90. Haas CS, Amin MA, Ruth JH, Allen BL, Ahmed S, Pakozdi A, et al. In Vivo Inhibition of Angiogenesis by Interleukin-13 Gene Therapy in a Rat Model of Rheumatoid Arthritis. Arthritis Rheum (2007) 56(8):2535-48. doi: $10.1002 /$ art.22823

91. Nabbe KC, van Lent PL, Holthuysen AE, Kolls JK, Verbeek S, van den Berg WB. FcgammaRI Up-Regulation Induced by Local Adenoviral-Mediated Interferon-Gamma Production Aggravates Chondrocyte Death During Immune Complex-Mediated Arthritis. Am J Pathol (2003) 163(2):743-52. doi: 10.1016/s0002-9440(10)63701-7

92. Zhu D, Zhao J, Lou A, Huang Q, OuYang Q, Zhu J, et al. Transforming Growth Factor $\beta 1$ Promotes Fibroblast-Like Synoviocytes Migration and Invasion via TGF- $\beta 1 /$ Smad Signaling in Rheumatoid Arthritis. Mol Cell Biochem (2019) 459(1-2):141-50. doi: 10.1007/s11010-019-03557-0

93. Galeazzi M, Sebastiani GD, Bazzichi L, Garcia Gonzalez E, Ravenni N, Giovannoni L, et al. SAT0196 Dekavil (F8-IL10), A Novel Therapeutic Approach for Rheumatoid Arthritis: Ongoing Phase IB Clinical Trial Results. Ann Rheumatic Dis (2015) 74(Suppl 2):726. doi: 10.1136/annrheumdis-2015-eular.3889

94. Vergunst CE, Tak PP. Chemokines: Their Role in Rheumatoid Arthritis. Curr Rheumatol Rep (2005) 7(5):382-8. doi: 10.1007/s11926-005-0026-7

95. Kuan WP, Tam LS, Wong CK, Ko FW, Li T, Zhu T, et al. CXCL 9 and CXCL 10 as Sensitive Markers of Disease Activity in Patients With Rheumatoid Arthritis. J Rheumatol (2010) 37(2):257-64. doi: 10.3899/jrheum.090769

96. Szekanecz Z, Vegvari A, Szabo Z, Koch AE. Chemokines and Chemokine Receptors in Arthritis. Front Biosci (Schol Ed) (2010) 2:153-67. doi: 10.2741/s53

97. Ruth JH, Haas CS, Park CC, Amin MA, Martinez RJ, Haines GK 3rd, et al. CXCL16-Mediated Cell Recruitment to Rheumatoid Arthritis Synovial Tissue and Murine Lymph Nodes Is Dependent Upon the MAPK Pathway. Arthritis Rheum (2006) 54(3):765-78. doi: 10.1002/art.21662

98. Tian Y, Terkawi MA, Onodera T, Alhasan H, Matsumae G, Takahashi D, et al. Blockade of XCL1/Lymphotactin Ameliorates Severity of Periprosthetic Osteolysis Triggered by Polyethylene-Particles. Front Immunol (2020) 11:1720-33. doi: 10.3389/fimmu.2020.01720

99. Miyabe Y, Miyabe C, Murooka TT, Kim EY, Newton GA, Kim ND, et al. Complement C5a Receptor is the Key Initiator of Neutrophil Adhesion Igniting Immune Complex-Induced Arthritis. Sci Immunol (2017) 2(7): eaaj2195. doi: 10.1126/sciimmunol.aaj2195

100. Lee JH, Kim B, Jin WJ, Kim HH, Ha H, Lee ZH. Pathogenic Roles of CXCL10 Signaling Through CXCR3 and TLR4 in Macrophages and T Cells: Relevance for Arthritis. Arthritis Res Ther (2017) 19(1):163. doi: 10.1186/ s13075-017-1353-6

101. Armas-González E, Domínguez-Luis MJ, Díaz-Martín A, Arce-Franco M, Castro-Hernández J, Danelon G, et al. Role of CXCL13 and CCL20 in the Recruitment of B Cells to Inflammatory Foci in Chronic Arthritis. Arthritis Res Ther (2018) 20(1):114. doi: 10.1186/s13075-018-1611-2

102. Isozaki T, Arbab AS, Haas CS, Amin MA, Arendt MD, Koch AE, et al. Evidence That CXCL16 is a Potent Mediator of Angiogenesis and is Involved in Endothelial Progenitor Cell Chemotaxis: Studies in Mice With K/BxN SerumInduced Arthritis. Arthritis Rheum (2013) 65(7):1736-46. doi: 10.1002/art.37981

103. Moschovakis GL, Bubke A, Friedrichsen M, Falk CS, Feederle R, Förster R. T Cell Specific Cxcr5 Deficiency Prevents Rheumatoid Arthritis. Sci Rep (2017) 7(1):8933. doi: 10.1038/s41598-017-08935-6
104. Boff D, Crijns H, Janssens R, Vanheule V, Menezes GB, Macari S, et al. The Chemokine Fragment CXCL9(74-103) Diminishes Neutrophil Recruitment and Joint Inflammation in Antigen-Induced Arthritis. J Leukoc Biol (2018) 104(2):413-22. doi: 10.1002/jlb.3ma1217-502r

105. Yang MH, Wu FX, Xie CM, Qing YF, Wang GR, Guo XL, et al. Expression of CC Chemokine Ligand 5 in Patients With Rheumatoid Arthritis and its Correlation With Disease Activity and Medication. Chin Med Sci J = Chungkuo i hsueh k'o hsueh tsa chih (2009) 24(1):50-4. doi: 10.1016/s1001-9294 (09)60059-6

106. Radstake TR, van der Voort R, ten Brummelhuis M, de Waal Malefijt M, Looman M, Figdor CG, et al. Increased Expression of CCL18, CCL19, and CCL17 by Dendritic Cells From Patients With Rheumatoid Arthritis, and Regulation by Fc Gamma Receptors. Ann Rheum Dis (2005) 64(3):359-67. doi: 10.1136/ard.2003.017566

107. Stankovic A, Slavic V, Stamenkovic B, Kamenov B, Bojanovic M, Mitrovic DR. Serum and Synovial Fluid Concentrations of CCL2 (MCP-1) Chemokine in Patients Suffering Rheumatoid Arthritis and Osteoarthritis Reflect Disease Activity. Bratislavske lekarske listy (2009) 110(10):641-6.

108. Iwamoto T, Okamoto H, Iikuni N, Takeuchi M, Toyama Y, Tomatsu T, et al. Monocyte Chemoattractant Protein-4 (MCP-4)/CCL13 is Highly Expressed in Cartilage From Patients With Rheumatoid Arthritis. Rheumatology (Oxford) (2006) 45(4):421-4. doi: 10.1093/rheumatology/kei209

109. Asquith DL, Bryce SA, Nibbs RJ. Targeting Cell Migration in Rheumatoid Arthritis. Curr Opin Rheumatol (2015) 27(2):204-11. doi: 10.1097/ bor. 0000000000000150

110. Haringman JJ, Smeets TJ, Reinders-Blankert P, Tak PP. Chemokine and Chemokine Receptor Expression in Paired Peripheral Blood Mononuclear Cells and Synovial Tissue of Patients With Rheumatoid Arthritis, Osteoarthritis, and Reactive Arthritis. Ann Rheum Dis (2006) 65(3):294300. doi: 10.1136/ard.2005.037176

111. Chen Z, Kim SJ, Essani AB, Volin MV, Vila OM, Swedler W, et al. Characterising the Expression and Function of CCL28 and its Corresponding Receptor, CCR10, in RA Pathogenesis. Ann Rheum Dis (2015) 74(10):1898-906. doi: 10.1136/annrheumdis-2013-204530

112. Bachelerie F, Ben-Baruch A, Burkhardt AM, Combadiere C, Farber JM, Graham GJ, et al. International Union of Basic and Clinical Pharmacology. [Corrected]. LXXXIX. Update on the Extended Family of Chemokine Receptors and Introducing a New Nomenclature for Atypical Chemokine Receptors. Pharmacol Rev (2014) 66(1):1-79. doi: 10.1124/pr.113.007724

113. Talbot J, Bianchini FJ, Nascimento DC, Oliveira RD, Souto FO, Pinto LG, et al. CCR2 Expression in Neutrophils Plays a Critical Role in Their Migration Into the Joints in Rheumatoid Arthritis. Arthritis Rheumatol (Hoboken NJ) (2015) 67(7):1751-9. doi: 10.1002/art.39117

114. Li N, Wei W, Yin F, Chen M, Ma TR, Wu Q, et al. The Abnormal Expression of CCR4 and CCR6 on Tregs in Rheumatoid Arthritis. Int J Clin Exp Med (2015) 8(9):15043-53.

115. Haringman JJ, Ludikhuize J, Tak PP. Chemokines in Joint Disease: The Key to Inflammation? Ann Rheum Dis (2004) 63(10):1186-94. doi: 10.1136/ ard.2004.020529

116. Yokoyama W, Kohsaka H, Kaneko K, Walters M, Takayasu A, Fukuda S, et al. Abrogation of CC Chemokine Receptor 9 Ameliorates CollagenInduced Arthritis of Mice. Arthritis Res Ther (2014) 16(5):445. doi: 10.1186/s13075-014-0445-9

117. Rump L, Mattey DL, Kehoe O, Middleton J. An Initial Investigation Into Endothelial CC Chemokine Expression in the Human Rheumatoid Synovium. Cytokine (2017) 97:133-40. doi: 10.1016/j.cyto.2017.05.023

118. Wengner AM, Höpken UE, Petrow PK, Hartmann S, Schurigt U, Bräuer R, et al. CXCR5- and CCR7-Dependent Lymphoid Neogenesis in a Murine Model of Chronic Antigen-Induced Arthritis. Arthritis Rheum (2007) 56 (10):3271-83. doi: 10.1002/art.22939

119. Yamaguchi A, Nozawa K, Fujishiro M, Kawasaki M, Suzuki F, Takamori K, et al. CC Motif Chemokine Ligand 13 is Associated With Rheumatoid Arthritis Pathogenesis. Modern Rheumatol (2013) 23(5):856-63. doi: 10.1007/s10165-012-0752-4

120. Flytlie HA, Hvid M, Lindgreen E, Kofod-Olsen E, Petersen EL, Jørgensen A, et al. Expression of MDC/CCL22 and its Receptor CCR4 in Rheumatoid Arthritis, Psoriatic Arthritis and Osteoarthritis. Cytokine (2010) 49(1):24-9. doi: 10.1016/j.cyto.2009.10.005 
121. Jordan LA, Erlandsson MC, Fenner BF, Davies R, Harvey AK, Choy EH, et al. Inhibition of CCL3 Abrogated Precursor Cell Fusion and Bone Erosions in Human Osteoclast Cultures and Murine Collagen-Induced Arthritis. Rheumatology (Oxford) (2018) 57(11):2042-52. doi: 10.1093/ rheumatology/key196

122. Amat M, Benjamim CF, Williams LM, Prats N, Terricabras E, Beleta J, et al. Pharmacological Blockade of CCR1 Ameliorates Murine Arthritis and Alters Cytokine Networks In Vivo. Br J Pharmacol (2006) 149(6):666-75. doi: $10.1038 /$ sj.bjp. 0706912

123. Brühl H, Cihak J, Plachý J, Kunz-Schughart L, Niedermeier M, Denzel A, et al. Targeting of Gr-1+,CCR2+ Monocytes in Collagen-Induced Arthritis. Arthritis Rheum (2007) 56(9):2975-85. doi: 10.1002/art.22854

124. Vierboom MP, Zavodny PJ, Chou CC, Tagat JR, Pugliese-Sivo C, Strizki J, et al. Inhibition of the Development of Collagen-Induced Arthritis in Rhesus Monkeys by a Small Molecular Weight Antagonist of CCR5. Arthritis Rheum (2005) 52(2):627-36. doi: 10.1002/art.20850

125. Dairaghi DJ, Zhang P, Wang Y, Seitz LC, Johnson DA, Miao S, et al. Pharmacokinetic and Pharmacodynamic Evaluation of the Novel CCR1 Antagonist CCX354 in Healthy Human Subjects: Implications for Selection of Clinical Dose. Clin Pharmacol Ther (2011) 89(5):726-34. doi: 10.1038/clpt.2011.33

126. Vergunst CE, Gerlag DM, von Moltke L, Karol M, Wyant T, Chi X, et al. MLN3897 Plus Methotrexate in Patients With Rheumatoid Arthritis: Safety, Efficacy, Pharmacokinetics, and Pharmacodynamics of an Oral CCR1 Antagonist in a Phase IIa, Double-Blind, Placebo-Controlled, Randomized, Proof-of-Concept Study. Arthritis Rheum (2009) 60(12):3572-81. doi: $10.1002 /$ art.24978

127. Panezai J, Ali A, Ghaffar A, Benchimol D, Altamash M, Klinge B, et al. Upregulation of Circulating Inflammatory Biomarkers Under the Influence of Periodontal Disease in Rheumatoid Arthritis Patients. Cytokine (2020) 131:155117. doi: 10.1016/j.cyto.2020.155117

128. Nanki T, Urasaki Y, Imai T, Nishimura M, Muramoto K, Kubota T, et al. Inhibition of Fractalkine Ameliorates Murine Collagen-Induced Arthritis. J Immunol (Baltimore Md: 1950) (2004) 173(11):7010-6. doi: 10.4049/ jimmunol.173.11.7010

129. Endres M, Andreas K, Kalwitz G, Freymann U, Neumann K, Ringe J, et al. Chemokine Profile of Synovial Fluid From Normal, Osteoarthritis and Rheumatoid Arthritis Patients: CCL25, CXCL10 and XCL1 Recruit Human Subchondral Mesenchymal Progenitor Cells. Osteoarthr Cartil (2010) 18(11):1458-66. doi: 10.1016/j.joca.2010.08.003

130. Malemud CJ. The Role of the JAK/STAT Signal Pathway in Rheumatoid Arthritis. Ther Adv Musculoskelet Dis (2018) 10(5-6):117-27. doi: 10.1177/ $1759720 \times 18776224$

131. Schett G, Tohidast-Akrad M, Smolen JS, Schmid BJ, Steiner CW, Bitzan P, et al. Activation, Differential Localization, and Regulation of the Stress-Activated Protein Kinases, Extracellular Signal-Regulated Kinase, C-JUN N-Terminal Kinase, and P38 Mitogen-Activated Protein Kinase, in Synovial Tissue and Cells in Rheumatoid Arthritis. Arthritis Rheum (2000) 43(11):2501-12. doi: 10.1002/1529-0131(200011)43:11<2501::Aid-anr18>3.0.Co;2-k

132. Schett G, Zwerina J, Firestein G. The P38 Mitogen-Activated Protein Kinase (MAPK) Pathway in Rheumatoid Arthritis. Ann Rheum Dis (2008) 67 (7):909-16. doi: 10.1136/ard.2007.074278

133. Umar S, Palasiewicz K, Van Raemdonck K, Volin MV, Romay B, Amin MA, et al. IRAK4 Inhibition: A Promising Strategy for Treating RA Joint Inflammation and Bone Erosion. Cell Mol Immunol (2020) 10:41412-23. doi: 10.1038/s41423-020-0433-8

134. Burrage PS, Mix KS, Brinckerhoff CE. Matrix Metalloproteinases: Role in Arthritis. Front Biosci (2006) 11:529-43. doi: 10.2741/1817

135. Liu Y, Yin H, Zhao M, Lu Q. TLR2 and TLR4 in Autoimmune Diseases: A Comprehensive Review. Clin Rev Allergy Immunol (2014) 47(2):136-47. doi: 10.1007/s12016-013-8402-y

136. Yang X, Li S, Zhao Y, Li S, Zhao T, Tai Y, et al. GRK2 Mediated Abnormal Transduction of PGE2-EP4-cAMP-CREB Signaling Induces the Imbalance of Macrophages Polarization in Collagen-Induced Arthritis Mice. Cells (2019) 8(12):1596. doi: 10.3390/cells8121596

137. Cheung TT, McInnes IB. Future Therapeutic Targets in Rheumatoid Arthritis? Semin Immunopathol (2017) 39(4):487-500. doi: 10.1007/ s00281-017-0623-3
138. Ciszak L, Pawlak E, Kosmaczewska A, Potoczek S, Frydecka I. Alterations in the Expression of Signal-Transducing CD3 Zeta Chain in T Cells From Patients With Chronic Inflammatory/Autoimmune Diseases. Arch Immunol Ther Exp (Warsz) (2007) 55(6):373-86. doi: 10.1007/s00005-007-0042-6

139. Yusuf-Makagiansar H, Anderson ME, Yakovleva TV, Murray JS, Siahaan TJ. Inhibition of LFA-1/ICAM-1 and VLA-4/VCAM-1 as a Therapeutic Approach to Inflammation and Autoimmune Diseases. Med Res Rev (2002) 22(2):146-67. doi: 10.1002/med.10001

140. Tedder TF. CD19: A Promising B Cell Target for Rheumatoid Arthritis. Nat Rev Rheumatol (2009) 5(10):572-7. doi: 10.1038/nrrheum.2009.184

141. Nakken B, Munthe LA, Konttinen YT, Sandberg AK, Szekanecz Z, Alex P, et al. B-Cells and Their Targeting in Rheumatoid Arthritis - Current Concepts and Future Perspectives. Autoimmun Rev (2011) 11(1):28-34. doi: 10.1016/j.autrev.2011.06.010

142. Maicas N, Ibáñez L, Alcaraz MJ, Úbeda A, Ferrándiz ML. Prostaglandin D2 Regulates Joint Inflammation and Destruction in Murine Collagen-Induced Arthritis. Arthritis Rheum (2012) 64(1):130-40. doi: 10.1002/art.30656

143. Chen Q, Muramoto K, Masaaki N, Ding Y, Yang H, Mackey M, et al. A Novel Antagonist of the Prostaglandin E(2) EP(4) Receptor Inhibits Th1 Differentiation and Th17 Expansion and Is Orally Active in Arthritis Models. Br J Pharmacol (2010) 160(2):292-310. doi: 10.1111/j.1476-5381.2010.00647.x

144. Caselli G, Bonazzi A, Lanza M, Ferrari F, Maggioni D, Ferioli C, et al. Pharmacological Characterisation of CR6086, a Potent Prostaglandin E(2) Receptor 4 Antagonist, as a New Potential Disease-Modifying AntiRheumatic Drug. Arthritis Res Ther (2018) 20(1):39. doi: 10.1186/s13075018-1537-8

145. Boehme MW, Gao IK, Norden C, Lemmel EM. Decrease in Circulating Endothelial Cell Adhesion Molecule and Thrombomodulin Levels During Oral Iloprost Treatment in Rheumatoid Arthritis Patients: Preliminary Results. Rheumatol Int (2006) 26(4):340-7. doi: 10.1007/s00296-004-0563-9

146. Carregaro V, Napimoga MH, Peres RS, Benevides L, Sacramento LA, Pinto LG, et al. Therapeutic Treatment of Arthritic Mice With 15-Deoxy $\Delta(12,14)$ Prostaglandin J(2) (15d-PGJ(2)) Ameliorates Disease Through the Suppression of Th17 Cells and the Induction of CD4(+)CD25(-)FOXP3(+) Cells. Mediators Inflammation (2016) 2016:9626427. doi: 10.1155/2016/ 9626427

147. Ahmad SF, Akoum A, Horne AW. Selective Modulation of the Prostaglandin F2 $\alpha$ Pathway Markedly Impacts on Endometriosis Progression in a Xenograft Mouse Model. Mol Hum Reprod (2015) 21(12):905-16. doi: $10.1093 / \mathrm{molehr} / \mathrm{gav} 056$

148. Chu YL, Huang QC, Huang RY, Yan JY, Chen XM, Zhen-Xiong XU, et al. Thromboxane A2 Receptor Induces Proliferation of Rheumatoid Arthritis Synovial Cells by Up-Regulation of Cyclooxygenase-2. Chin J Pathophysiol (2014) 30(6):1110-97. doi: 10.3969/j.issn.1000-4718.2014.06.026

149. Díaz-González F, Alten RH, Bensen WG, Brown JP, Sibley JT, Dougados M, et al. Clinical Trial of a Leucotriene B4 Receptor Antagonist, BIIL 284, in Patients With Rheumatoid Arthritis. Ann Rheum Dis (2007) 66(5):628-32. doi: 10.1136/ard.2006.062554

150. Xu M, Hong R, Zhang X, Zou H, Zhang Y, Hou Z, et al. CysLT1 Receptor Antagonist Alleviates Pathogenesis of Collagen-Induced Arthritis Mouse Model. Oncotarget (2017) 8(65):108418-29. doi: 10.18632/oncotarget.22664

151. Zhang L, Zhang X, Wu P, Li H, Jin S, Zhou X, et al. BML-111, a Lipoxin Receptor Agonist, Modulates the Immune Response and Reduces the Severity of Collagen-Induced Arthritis. Inflammation Res (2008) 57 (4):157-62. doi: 10.1007/s00011-007-7141-z

152. Svetlov SI, Barton JM, Olson MS. The Specific Binding of the PlateletActivating Factor (PAF) Receptor Antagonist WEB 2086 and the Benzodiazepine Flunitrazepam to Rat Hepatocytes. Life Sci (1996) 58(5):Pl 81-6. doi: 10.1016/0024-3205(95)02302-x

153. Mateen S, Rehman MT, Shahzad S, Naeem SS, Faizy AF, Khan AQ, et al. Anti-Oxidant and Anti-Inflammatory Effects of Cinnamaldehyde and Eugenol on Mononuclear Cells of Rheumatoid Arthritis Patients. Eur J Pharmacol (2019) 852:14-24. doi: 10.1016/j.ejphar.2019.02.031

154. Seymour M, Pétavy F, Chiesa F, Perry H, Lukey PT, Binks M, et al. Ultrasonographic Measures of Synovitis in an Early Phase Clinical Trial: A Double-Blind, Randomised, Placebo and Comparator Controlled Phase IIa Trial of GW274150 (a Selective Inducible Nitric Oxide Synthase Inhibitor) in Rheumatoid Arthritis. Clin Exp Rheumatol (2012) 30(2):254-61. 
155. Dey S, Bishayi B. Effect of iNOS Inhibitor LNMMA Along With Antibiotics Chloramphenicol or Ofloxacin in Murine Peritoneal Macrophages Regulates S.aureus Infection as Well as Inflammation: An In Vitro Study. Microb Pathog (2017) 105:307-20. doi: 10.1016/j.micpath.2017.02.031

156. Gui H, Liu X, Wang ZW, He DY, Su DF, Dai SM. Expression of Cannabinoid Receptor 2 and Its Inhibitory Effects on Synovial Fibroblasts in Rheumatoid Arthritis. Rheumatology (Oxford) (2014) 53(5):802-9. doi: 10.1093/ rheumatology/ket447

157. Fechtner S, Singh AK, Srivastava I, Szlenk CT, Muench TR, Natesan S, et al. Cannabinoid Receptor 2 Agonist JWH-015 Inhibits Interleukin-1 $\beta$-Induced Inflammation in Rheumatoid Arthritis Synovial Fibroblasts and in Adjuvant Induced Arthritis Rat via Glucocorticoid Receptor. Front Immunol (2019) 10:1027. doi: 10.3389/fimmu.2019.01027

158. Kinsey SG, Naidu PS, Cravatt BF, Dudley DT, Lichtman AH. Fatty Acid Amide Hydrolase Blockade Attenuates the Development of CollagenInduced Arthritis and Related Thermal Hyperalgesia in Mice. Pharmacol Biochem Behav (2011) 99(4):718-25. doi: 10.1016/j.pbb.2011.06.022

159. Burstein SH. N-Acyl Amino Acids (Elmiric Acids): Endogenous Signaling Molecules With Therapeutic Potential. Mol Pharmacol (2018) 93(3):228-38. doi: 10.1124/mol.117.110841

160. Zayed N, Afif H, Chabane N, Mfuna-Endam L, Benderdour M, MartelPelletier $\mathrm{J}$, et al. Inhibition of Interleukin-1beta-Induced Matrix Metalloproteinases 1 and 13 Production in Human Osteoarthritic Chondrocytes by Prostaglandin D2. Arthritis Rheum (2008) 58(11):353040. doi: 10.1002/art.23958

161. Duffin R, O'Connor RA, Crittenden S, Forster T, Yu C, Zheng X, et al. Prostaglandin $\mathrm{E}_{2}$ Constrains Systemic Inflammation Through an Innate Lymphoid Cell-IL-22 Axis. Sci (New York NY) (2016) 351(6279):1333-8. doi: 10.1126/science.aad9903

162. Takahashi Y, Tokuoka S, Masuda T, Hirano Y, Nagao M, Tanaka H, et al. Augmentation of Allergic Inflammation in Prostanoid IP Receptor Deficient Mice. Br J Pharmacol (2002) 137(3):315-22. doi: 10.1038/sj.bjp.0704872

163. Yokomizo T, Nakamura M, Shimizu T. Leukotriene Receptors as Potential Therapeutic Targets. J Clin Invest (2018) 128(7):2691-701. doi: 10.1172/ jci97946

164. Alten R, Gromnica-Ihle E, Pohl C, Emmerich J, Steffgen J, Roscher R, et al. Inhibition of Leukotriene B4-Induced CD11B/CD18 (Mac-1) Expression by BIIL 284, a New Long Acting LTB4 Receptor Antagonist, in Patients With Rheumatoid Arthritis. Ann Rheum Dis (2004) 63(2):170-6. doi: 10.1136/ ard.2002.004499

165. Dong H, Liu F, Ma F, Xu L, Pang L, Li X, et al. Montelukast Inhibits Inflammatory Response in Rheumatoid Arthritis Fibroblast-Like Synoviocytes. Int Immunopharmacol (2018) 61:215-21. doi: 10.1016/ j.intimp.2018.04.042

166. Venugopal N, Acharya P, Zarei M, Talahalli RR. Cysteinyl Leukotriene Receptor Antagonism: A Promising Pharmacological Strategy for Lowering the Severity of Arthritis. Inflammopharmacology (2019) 27(5):923-31. doi: 10.1007/s10787-019-00618-0

167. Ramon S, Bancos S, Serhan CN, Phipps RP. Lipoxin $\mathrm{A}_{4}$ Modulates Adaptive Immunity by Decreasing Memory B-Cell Responses via an ALX/FPR2Dependent Mechanism. Eur J Immunol (2014) 44(2):357-69. doi: 10.1002/ eji. 201343316

168. Hashimoto A, Hayashi I, Murakami Y, Sato Y, Kitasato H, Matsushita R, et al. Antiinflammatory Mediator Lipoxin A4 and Its Receptor in Synovitis of Patients With Rheumatoid Arthritis. J Rheumatol (2007) 34(11):2144-53.

169. Kim N, Lannan KL, Thatcher TH, Pollock SJ, Woeller CF, Phipps RP. Lipoxin B(4) Enhances Human Memory B Cell Antibody Production via Upregulating Cyclooxygenase-2 Expression. I Immunol (Baltimore Md: 1950) (2018) 201(11):3343-51. doi: 10.4049/jimmunol.1700503

170. Zarbock A, Polanowska-Grabowska RK, Ley K. Platelet-NeutrophilInteractions: Linking Hemostasis and Inflammation. Blood Rev (2007) 21 (2):99-111. doi: 10.1016/j.blre.2006.06.001

171. Manfredi AA, Baldini M, Camera M, Baldissera E, Brambilla M, Peretti G, et al. Anti-Tnf $\alpha$ Agents Curb Platelet Activation in Patients With Rheumatoid Arthritis. Ann Rheum Dis (2016) 75(8):1511-20. doi: 10.1136/ annrheumdis-2015-208442

172. Mateen S, Moin S, Shahzad S, Khan AQ. Level of Inflammatory Cytokines in Rheumatoid Arthritis Patients: Correlation With 25-Hydroxy Vitamin D and Reactive Oxygen Species. PloS One (2017) 12(6):e0178879. doi: 10.1371/ journal.pone.0178879

173. Wang KC, Liu YC, El-Shazly M, Shih SP, Du YC, Hsu YM, et al. The Antioxidant From Ethanolic Extract of Rosa Cymosa Fruits Activates Phosphatase and Tensin Homolog In Vitro and In Vivo: A New Insight on Its Antileukemic Effect. Int J Mol Sci (2019) 20(8):1935-58. doi: 10.3390/ ijms 20081935

174. Liu Y, Wei W, Hong C, Wang Y, Sun X, Ma J, et al. Calreticulin Induced Endothelial ICAM-1 Up-Regulation Associated With Tristetraprolin Expression Alteration Through PI3K/Akt/eNOS/p38 MAPK Signaling Pathway in Rheumatoid Arthritis. Mol Immunol (2019) 107:10-20. doi: 10.1016/j.molimm.2019.01.005

175. Takatani Y, Ono K, Suzuki H, Inaba M, Sawada M, Matsuda N. Inducible Nitric Oxide Synthase During the Late Phase of Sepsis Is Associated With Hypothermia and Immune Cell Migration. Lab Invest (2018) 98(5):629-39. doi: 10.1038/s41374-018-0021-z

176. Di Marzo V, Bifulco M, De Petrocellis L. The Endocannabinoid System and its Therapeutic Exploitation. Nat Rev Drug Discovery (2004) 3(9):771-84. doi: $10.1038 / \mathrm{nrd} 1495$

177. Ciechomska M, Roszkowski L, Maslinski W. DNA Methylation as a Future Therapeutic and Diagnostic Target in Rheumatoid Arthritis. Cells (2019) 8 (9):953-68. doi: 10.3390/cells8090953

178. Wang J, Yan S, Lu H, Wang S, Xu D. METTL3 Attenuates LPS-Induced Inflammatory Response in Macrophages via NF- $\kappa b$ Signaling Pathway. Mediators Inflammation (2019) 2019:3120391-. doi: 10.1155/2019/3120391

179. Seong AR, Yoo JY, Choi K, Lee MH, Lee YH, Lee J, et al. Delphinidin, a Specific Inhibitor of Histone Acetyltransferase, Suppresses Inflammatory Signaling via Prevention of NF- $\mathrm{kb}$ Acetylation in Fibroblast-Like Synoviocyte MH7A Cells. Biochem Biophys Res Commun (2011) 410 (3):581-6. doi: 10.1016/j.bbrc.2011.06.029

180. Yang GH, Zhang C, Wang N, Meng Y, Wang YS. Anacardic Acid Suppresses Fibroblast-Like Synoviocyte Proliferation and Invasion and Ameliorates Collagen-Induced Arthritis in a Mouse Model. Cytokine (2018) 111:350-6. doi: 10.1016/j.cyto.2018.09.008

181. Ntougkos E, Chouvardas P, Roumelioti F, Ospelt C, Frank-Bertoncelj M, Filer A, et al. Genomic Responses of Mouse Synovial Fibroblasts During Tumor Necrosis Factor-Driven Arthritogenesis Greatly Mimic Those in Human Rheumatoid Arthritis. Arthritis Rheumatol (Hoboken NJ) (2017) 69(8):1588-600. doi: 10.1002/art.40128

182. Choo QY, Ho PC, Tanaka Y, Lin HS. Histone Deacetylase Inhibitors MS-275 and SAHA Induced Growth Arrest and Suppressed LipopolysaccharideStimulated NF-kappaB P65 Nuclear Accumulation in Human Rheumatoid Arthritis Synovial Fibroblastic E11 Cells. Rheumatology (Oxford) (2010) 49 (8):1447-60. doi: 10.1093/rheumatology/keq108

183. Angiolilli C, Baeten DL, Radstake TR, Reedquist KA. The Acetyl Code in Rheumatoid Arthritis and Other Rheumatic Diseases. Epigenomics (2017) 9 (4):447-61. doi: 10.2217/epi-2016-0136

184. Lee HR, Yoo SJ, Kim J, Yoo IS, Park CK, Kang SW. The Effect of Nicotinamide Adenine Dinucleotide Phosphate Oxidase 4 on Migration and Invasion of Fibroblast-Like Synoviocytes in Rheumatoid Arthritis. Arthritis Res Ther (2020) 22(1):116. doi: 10.1186/s13075-020-02204-0

185. Park JK, Jang YJ, Oh BR, Shin J, Bae D, Ha N, et al. Therapeutic Potential of CKD-506, a Novel Selective Histone Deacetylase 6 Inhibitor, in a Murine Model of Rheumatoid Arthritis. Arthritis Res Ther (2020) 22(1):176. doi: 10.1186/s13075-020-02258-0

186. Oh BR, Suh DH, Bae D, Ha N, Choi YI, Yoo HJ, et al. Therapeutic Effect of a Novel Histone Deacetylase 6 Inhibitor, CKD-L, on Collagen-Induced Arthritis In Vivo and Regulatory T Cells in Rheumatoid Arthritis In Vitro. Arthritis Res Ther (2017) 19(1):154. doi: 10.1186/s13075-017-1357-2

187. Li M, Liu X, Sun X, Wang Z, Guo W, Hu F, et al. Therapeutic Effects of NKHDAC-1, a Novel Histone Deacetylase Inhibitor, on Collagen-Induced Arthritis Through the Induction of Apoptosis of Fibroblast-Like Synoviocytes. Inflammation (2013) 36(4):888-96. doi: 10.1007/s10753-013-9616-0

188. Ahmed S, Riegsecker S, Beamer M, Rahman A, Bellini JV, Bhansali P, et al. Largazole, a Class I Histone Deacetylase Inhibitor, Enhances TNF- $\alpha$ Induced ICAM-1 and VCAM-1 Expression in Rheumatoid Arthritis Synovial Fibroblasts. Toxicol Appl Pharmacol (2013) 270(2):87-96. doi: 10.1016/j.taap.2013.04.014 
189. Vojinovic J, Damjanov N. HDAC Inhibition in Rheumatoid Arthritis and Juvenile Idiopathic Arthritis. Mol Med (2011) 17(5-6):397-403. doi: 10.2119/ molmed.2011.00030

190. Park-Min KH, Lim E, Lee MJ, Park SH, Giannopoulou E, Yarilina A, et al. Inhibition of Osteoclastogenesis and Inflammatory Bone Resorption by Targeting BET Proteins and Epigenetic Regulation. Nat Commun (2014) 5:5418. doi: $10.1038 /$ ncomms6418

191. Xiao Y, Liang L, Huang M, Qiu Q, Zeng S, Shi M, et al. Bromodomain and Extra-Terminal Domain Bromodomain Inhibition Prevents Synovial Inflammation via Blocking Iкb Kinase-Dependent NF- $\mathrm{kb}$ Activation in Rheumatoid Fibroblast-Like Synoviocytes. Rheumatology (Oxford) (2016) 55(1):173-84. doi: 10.1093/rheumatology/kev312

192. Shao L, Hou C. miR-138 Activates NF-kb Signaling and PGRN to Promote Rheumatoid Arthritis via Regulating HDAC4. Biochem Biophys Res Commun (2019) 519(1):166-71. doi: 10.1016/j.bbrc.2019.08.092

193. Hou C, Wang D, Zhang L. MicroRNA-34a-3p Inhibits Proliferation of Rheumatoid Arthritis Fibroblast-Like Synoviocytes. Mol Med Rep (2019) 20 (3):2563-70. doi: 10.3892/mmr.2019.10516

194. Liu K, Zhang Y, Liu L, Yuan Q. miR-125 Regulates PI3K/Akt/mTOR Signaling Pathway in Rheumatoid Arthritis Rats via PARP2. Biosci Rep (2019) 39(1):BSR20180890. doi: 10.1042/bsr20180890

195. Zhou Y, Li S, Chen P, Yang B, Yang J, Liu R, et al. MicroRNA-27b-3p Inhibits Apoptosis of Chondrocyte in Rheumatoid Arthritis by Targeting HIPK2. Artif Cells Nanomed Biotechnol (2019) 47(1):1766-71. doi: 10.1080/ 21691401.2019.1607362

196. Qu SP, Li GW, Ma H, Xing Q. MicroRNA-193a-3p Participates in the Progression of Rheumatoid Arthritis by Regulating Proliferation and Apoptosis of MH7A Cells Through Targeting IGFBP5. Eur Rev Med Pharmacol Sci (2019) 23(11):4850-7. doi: 10.26355/eurrev_201906_18072

197. Chen Y, Wang W, Chen Y, Tang Q, Zhu W, Li D, et al. MicroRNA-19a-3p Promotes Rheumatoid Arthritis Fibroblast-Like Synoviocytes via Targeting SOCS3. J Cell Biochem(2019) 120(7):11624-32. doi: 10.1002/jcb.28442

198. Qiang J, Lv T, Wu Z, Yang X. Down-Regulation of microRNA-142-3p Inhibits the Aggressive Phenotypes of Rheumatoid Arthritis Fibroblast-Like Synoviocytes Through Inhibiting Nuclear Factor-kb Signaling. Biosci Rep (2019) 39(7):3245-58. doi: 10.1042/bsr20190700

199. Qu Y, Zhang YP, Wu J, Jie LG, Deng JX, Zhao DB, et al. Downregulated microRNA-135a Ameliorates Rheumatoid Arthritis by Inactivation of the Phosphatidylinositol 3-Kinase/AKT Signaling Pathway via Phosphatidylinositol 3-Kinase Regulatory Subunit 2. J Cell Physiol (2019) 234(10):17663-76. doi: 10.1002/jcp.28390

200. Zheng J, Zhu L, Iok In I, Chen Y, Jia N, Zhu W. Bone Marrow-Derived Mesenchymal Stem Cells-Secreted Exosomal microRNA-192-5p Delays Inflammatory Response in Rheumatoid Arthritis. Int Immunopharmacol (2020) 78:105985. doi: 10.1016/j.intimp.2019.105985

201. Li Z, Chen H, Wang F, Wang Z, Zhao Q, Liu S, et al. Down-Regulation of microRNA-98 Promoted Apoptosis of TNF- $\alpha$ Stimulated Human Fibroblast-Like Synoviocytes via Up-Regulating IL-10. Gene (2019) 706:124-30. doi: 10.1016/j.gene.2019.05.019

202. Zhang Y, Yan N, Wang X, Chang Y, Wang Y. MiR-129-5p Regulates Cell Proliferation and Apoptosis via IGF-1r/Src/ERK/Egr-1 Pathway in RAFibroblast-Like Synoviocytes. Biosci Rep (2019) 39(12):BSR20192009. doi: 10.1042/bsr20192009

203. Huang Z, Xing S, Liu M, Deng W, Wang Y, Huang Z, et al. MiR-26a-5p Enhances Cells Proliferation, Invasion, and Apoptosis Resistance of Fibroblast-Like Synoviocytes in Rheumatoid Arthritis by Regulating PTEN/PI3K/AKT Pathway. Biosci Rep (2019) 39(7):BSR20182192. doi: 10.1042/bsr20182192

204. Abo ElAtta AS, Ali YBM, Bassyouni IH, Talaat RM. Upregulation of miR221/222 Expression in Rheumatoid Arthritis (RA) Patients: Correlation With Disease Activity. Clin Exp Med (2019) 19(1):47-53. doi: 10.1007/ s10238-018-0524-3

205. Yu S, Lu Y, Zong M, Tan Q, Fan L. Hypoxia-Induced miR-191-C/Ebp $\beta$ Signaling Regulates Cell Proliferation and Apoptosis of Fibroblast-Like Synoviocytes From Patients With Rheumatoid Arthritis. Arthritis Res Ther (2019) 21(1):78. doi: 10.1186/s13075-019-1861-7

206. Cai Y, Jiang C, Zhu J, Xu K, Ren X, Xu L, et al. miR-449a Inhibits Cell Proliferation, Migration, and Inflammation by Regulating High-Mobility
Group Box Protein 1 and Forms a Mutual Inhibition Loop With Yin Yang 1 in Rheumatoid Arthritis Fibroblast-Like Synoviocytes. Arthritis Res Ther (2019) 21(1):134. doi: 10.1186/s13075-019-1920-0

207. Wang Y, Xu N, Zhao S, Jiao T, Fu W, Yang L, et al. miR-410-3p Suppresses Cytokine Release From Fibroblast-Like Synoviocytes by Regulating NF- $\mathrm{kb}$ Signaling in Rheumatoid Arthritis. Inflammation (2019) 42(1):331-41. doi: 10.1007/s10753-018-0896-2

208. Li D, Zhou Q, Hu G, Wang G. MiRNA-506 Inhibits Rheumatoid Arthritis Fibroblast-Like Synoviocytes Proliferation and Induces Apoptosis by Targetting TLR4. Biosci Rep (2019) 39(5):BSR20182500. doi: 10.1042/ BSR20182500

209. Lin K, Su HY, Jiang LF, Chu TG, Li Z, Chen XL, et al. Influences of miR-320a on Proliferation and Apoptosis of Fibroblast-Like Synoviocytes in Rheumatoid Arthritis Through Targeting MAPK-Erk1/2. Eur Rev Med Pharmacol Sci (2019) 23(5):1907-14. doi: 10.26355/eurrev_201903_17228

210. Ren B, Liu J, Wu K, Zhang J, Lv Y, Wang S, et al. TNF- $\alpha$-Elicited miR-29b Potentiates Resistance to Apoptosis in Peripheral Blood Monocytes From Patients With Rheumatoid Arthritis. Apoptosis Int J Programmed Cell Death (2019) 24(11-12):892-904. doi: 10.1007/s10495-019-01567-3

211. Wang Y, Feng T, Duan S, Shi Y, Li S, Zhang X, et al. miR-155 Promotes Fibroblast-Like Synoviocyte Proliferation and Inflammatory Cytokine Secretion in Rheumatoid Arthritis by Targeting FOXO3a. Exp Ther Med (2020) 19(2):1288-96. doi: 10.3892/etm.2019.8330

212. Wang X, Tang K, Wang Y, Chen Y, Yang M, Gu C, et al. Elevated microRNA -145-5p Increases Matrix Metalloproteinase-9 by Activating the Nuclear Factor-kb Pathway in Rheumatoid Arthritis. Mol Med Rep (2019) 20(3):2703-11. doi: 10.3892/mmr.2019.10499

213. Yang QY, Yang KP, Li ZZ. MiR-22 Restrains Proliferation of Rheumatoid Arthritis by Targeting IL6R and may be Concerned With the Suppression of NF-kb Pathway. Kaohsiung J Med Sci (2020) 36(1):20-6. doi: 10.1002/ kjm2.12124

214. Zhang C, Fang L, Liu X, Nie T, Li R, Cui L, et al. miR-22 Inhibits Synovial Fibroblasts Proliferation and Proinflammatory Cytokine Production in RASF via Targeting SIRT1. Gene (2020) 724:144144. doi: 10.1016/j.gene. 2019.144144

215. Wang J, Wang Y, Zhang H, Chang J, Lu M, Gao W, et al. Identification of a Novel microRNA-141-3p/Forkhead Box C1/ $\beta$-Catenin Axis Associated With Rheumatoid Arthritis Synovial Fibroblast Function In Vivo and In Vitro. Theranostics (2020) 10(12):5412-34. doi: 10.7150/thno.45214

216. Wei Q, Lv F, Zhang H, Wang X, Geng Q, Zhang X, et al. MicroRNA-101-3p Inhibits Fibroblast-Like Synoviocyte Proliferation and Inflammation in Rheumatoid Arthritis by Targeting PTGS2. Biosci Rep (2020) 40(1): BSR20191136. doi: 10.1042/bsr20191136

217. Fang L, Xu XF, Lu Y, Wu YY, Li JJ. MicroRNA-495 Attenuates Proliferation and Inflammatory Response in Rheumatoid Arthritis Fibroblast-Like Synoviocytes Through Attenuating $\beta$-Catenin Pathway. J Biol Regul Homeostat Agents (2020) 34(3):837-44. doi: 10.23812/20-47-a-22

218. Najm A, Masson FM, Preuss P, Georges S, Ory B, Quillard T, et al. MicroRNA-17-5p Reduces Inflammation and Bone Erosions in Mice With Collagen-Induced Arthritis and Directly Targets the JAK/STAT Pathway in Rheumatoid Arthritis Fibroblast-Like Synoviocytes. Arthritis Rheumatol (Hoboken NJ) (2020) 72(12):2030-9. doi: 10.1002/art.41441

219. Zhu J, Wang J, Huang J, Du W, He Y, Pan H, et al. MicroRNA-140-5p Regulates the Proliferation, Apoptosis and Inflammation of RA FLSs by Repressing STAT3. Exp Ther Med (2021) 21(2):171. doi: 10.3892/ etm.2020.9602

220. Fu D, Xiao C, Xie Y, Gao J, Ye S. MiR-3926 Inhibits Synovial Fibroblasts Proliferation and Inflammatory Cytokines Secretion Through Targeting Toll Like Receptor 5. Gene (2019) 687:200-6. doi: 10.1016/j.gene.2018.11.014

221. Liu L, Zuo Y, Xu Y, Zhang Z, Li Y, Pang J. MiR-613 Inhibits Proliferation and Invasion and Induces Apoptosis of Rheumatoid Arthritis Synovial Fibroblasts by Direct Down-Regulation of DKK1. Cell Mol Biol Lett (2019) 24:8. doi: 10.1186/s11658-018-0130-0

222. Li G, Qiu Z. Deletion of miR-15 Protects Against Rheumatoid Arthritis via Deregulating Its Target Gene BCL2L2 and Repressing NF-kb Pathway. Ann Clin Lab Sci (2019) 49(5):581-9.

223. Liu XG, Zhang Y, Ju WF, Li CY, Mu YC. MiR-21 Relieves Rheumatoid Arthritis in Rats via targeting Wnt signaling pathway. Eur Rev Med 
Pharmacol Sci (2019) 23(3 Suppl):96-103. doi: 10.26355/eurrev_ 201908_18635

224. Wei H, Wu Q, Shi Y, Luo A, Lin S, Feng X, et al. MicroRNA-15a/16/SOX5 Axis Promotes Migration, Invasion and Inflammatory Response in Rheumatoid Arthritis Fibroblast-Like Synoviocytes. Aging (2020) 12 (14):14376-90. doi: 10.18632/aging.103480

225. Yu Z, Liu H, Fan J, Chen F, Liu W. MicroRNA-155 Participates in the Expression of LSD1 and Proinflammatory Cytokines in Rheumatoid Synovial Cells. Mediators Inflammation (2020) 2020:4092762. doi: 10.1155/2020/4092762

226. Jiang L, Cao S. Role of microRNA-26a in Cartilage Injury and Chondrocyte Proliferation and Apoptosis in Rheumatoid Arthritis Rats by Regulating Expression of CTGF. J Cell Physiol (2020) 235(2):979-92. doi: 10.1002/ jcp. 29013

227. Liu D, Fang Y, Rao Y, Tan W, Zhou W, Wu X, et al. Synovial FibroblastDerived Exosomal microRNA-106b Suppresses Chondrocyte Proliferation and Migration in Rheumatoid Arthritis via Down-Regulation of PDK4. J Mol Med (Berlin Germany) (2020) 98(3):409-23. doi: 10.1007/s00109020-01882-2

228. Taha M, Shaker OG, Abdelsalam E, Taha N. Serum a Proliferation-Inducing Ligand and MicroRNA-223 Are Associated With Rheumatoid Arthritis: Diagnostic and Prognostic Implications. Mol Med (2020) 26(1):92. doi: 10.1186/s10020-020-00199-7

229. Huang Y, Chen K, Yu H, Chen D, Deng L, Zhang Y, et al. Up-Regulated microRNA-411 or Declined RIPK1 Inhibits Proliferation and Promotes Apoptosis of Synoviocytes in Rheumatoid Arthritis Mice via decreased NF-KB pathway. Cell Cycle (Georgetown Tex) (2020) 19(6):666-83. doi: 10.1080/15384101.2020.1717033

230. Lee WS, Yasuda S, Kono M, Kudo Y, Shimamura S, Kono M, et al. MicroRNA-9 Ameliorates Destructive Arthritis Through Down-Regulation of NF-kb1-RANKL Pathway in Fibroblast-Like Synoviocytes. Clin Immunol (2020) 212:108348. doi: 10.1016/j.clim.2020.108348

231. Chen J, Liu M, Luo X, Peng L, Zhao Z, He C, et al. Exosomal miRNA-486-5p Derived From Rheumatoid Arthritis Fibroblast-Like Synoviocytes Induces Osteoblast Differentiation Through the Tob1/BMP/Smad Pathway. Biomater Sci (2020) 8(12):3430-42. doi: 10.1039/c9bm01761e

232. Sui X, Liu H, Zhou Y. Expression of miR-495 and miR-326 in Peripheral Blood of Rheumatoid Arthritis Patients and Its Significance. Exp Ther Med (2020) 20(4):3766-74. doi: 10.3892/etm.2020.9124

233. Song AF, Kang L, Wang YF, Wang M. MiR-34a-5p Inhibits Fibroblast-Like Synoviocytes Proliferation via XBP1. Eur Rev Med Pharmacol Sci (2020) 24 (22):11675-82. doi: 10.26355/eurrev_202011_23812

234. Xie Z, Shen P, Qu Y, Xu J, Zheng C, Gao Y, et al. MiR-20a Inhibits the Progression of Human Arthritis Fibroblast-Like Synoviocytes and Inflammatory Factor Expression by Targeting ADAM10. Environ Toxicol (2020) 35(8):867-78. doi: 10.1002/tox.22923

235. Dinesh P, Kalaiselvan S, Sujitha S, Rasool M. MiR-145-5p Mitigates Dysregulated Wnt1/B-Catenin Signaling Pathway in Rheumatoid Arthritis. Int Immunopharmacol (2020) 82:106328. doi: 10.1016/j.intimp.2020.106328

236. Wang X, Gong S, Pu D, Hu N, Wang Y, Fan P, et al. Up-Regulation of miR365 Promotes the Apoptosis and Restrains Proliferation of Synoviocytes Through Downregulation of IGF1 and the Inactivation of the PI3K/AKT/ mTOR Pathway in Mice With Rheumatoid Arthritis. Int Immunopharmacol (2020) 79:106067. doi: 10.1016/j.intimp.2019.106067

237. Wu H, Zhou X, Wang X, Cheng W, Hu X, Wang Y, et al. miR-34a in Extracellular Vesicles From Bone Marrow Mesenchymal Stem Cells Reduces Rheumatoid Arthritis Inflammation via the Cyclin I/ATM/ATR/p53 Axis. J Cell Mol Med (2021) 25(4):1896-910. doi: 10.1111/jcmm.15857

238. Yang B, Ge Y, Zhou Y, Wang J, Xie X, Li S, et al. miR-124a Inhibits the Proliferation and Inflammation in Rheumatoid Arthritis Fibroblast-Like Synoviocytes via Targeting PIK3/NF-kb Pathway. Cell Biochem Funct (2019) 37(4):208-15. doi: 10.1002/cbf.3386

239. Li Z, Li Y, Li Q, Zhang Z, Jiang L, Li X. Role of miR-9-5p in Preventing Peripheral Neuropathy in Patients With Rheumatoid Arthritis by Targeting REST/miR-132 Pathway. In Vitro Cell Dev Biol Anim (2019) 55(1):52-61. doi: 10.1007/s11626-018-0310-2

240. Zhao F, Dong J, Guo J, Bi L. Inhibiting Role of Long non-Coding RNA LINC01197 in Inflammation in Rheumatoid Arthritis Through the
microRNA-150/THBS2 Axis. Exp Cell Res (2020) 394(2):112136. doi: 10.1016/j.yexcr.2020.112136

241. Rao Y, Fang Y, Tan W, Liu D, Pang Y, Wu X, et al. Delivery of Long NonCoding RNA NEAT1 by Peripheral Blood Mononuclear Cells-Derived Exosomes Promotes the Occurrence of Rheumatoid Arthritis via the MicroRNA-23a/MDM2/SIRT6 Axis. Front Cell Dev Biol (2020) 8:551681. doi: $10.3389 /$ fcell.2020.551681

242. Xiao J, Wang R, Zhou W, Cai X, Ye Z. LncRNA NEAT1 Regulates the Proliferation and Production of the Inflammatory Cytokines in Rheumatoid Arthritis Fibroblast-Like Synoviocytes by Targeting miR-204-5p. Hum Cell (2021) 34(2):372-82. doi: 10.1007/s13577-020-00461-4

243. Chen J, Luo X, Liu M, Peng L, Zhao Z, He C, et al. Silencing Long nonCoding RNA NEAT1 Attenuates Rheumatoid Arthritis via the MAPK/ERK Signalling Pathway by Downregulating microRNA-129 and microRNA-204. RNA Biol (2021) 18(5):657-68. doi: 10.1080/15476286.2020.1857941

244. Wang Y, Hou L, Yuan X, Xu N, Zhao S, Yang L, et al. LncRNA NEAT1 Targets Fibroblast-Like Synoviocytes in Rheumatoid Arthritis via the miR410-3p/YY1 Axis. Front Immunol (2020) 11:1975. doi: 10.3389/ fimmu.2020.01975

245. Tang J, Yi S, Liu Y. Long non-Coding RNA PVT1 can Regulate the Proliferation and Inflammatory Responses of Rheumatoid Arthritis Fibroblast-Like Synoviocytes by Targeting microRNA-145-5p. Hum Cell (2020) 33(4):1081-90. doi: 10.1007/s13577-020-00419-6

246. Wang J, Kong X, Hu H, Shi S. Knockdown of Long non-Coding RNA PVT1 Induces Apoptosis of Fibroblast-Like Synoviocytes Through Modulating miR-543-Dependent SCUBE2 in Rheumatoid Arthritis. J Orthopaed Surg Res (2020) 15(1):142. doi: 10.1186/s13018-020-01641-6

247. Zhang CW, Wu X, Liu D, Zhou W, Tan W, Fang YX, et al. Long non-Coding RNA PVT1 Knockdown Suppresses Fibroblast-Like Synoviocyte Inflammation and Induces Apoptosis in Rheumatoid Arthritis Through Demethylation of Sirt6. J Biol Eng (2019) 13:60. doi: 10.1186/s13036-019-0184-1

248. Qing P, Liu Y. Inhibitory Role of Long non-Coding RNA OIP5-AS1 in Rheumatoid Arthritis Progression Through the microRNA-448Paraoxonase 1-Toll-Like Receptor 3-Nuclear Factor $\mathrm{kb}$ Axis. Exp Physiol (2020) 105(10):1708-19. doi: 10.1113/ep088608

249. Zheng J, Zeng P, Zhang H, Zhou Y, Liao J, Zhu W, et al. Long Noncoding RNA ZFAS1 Silencing Alleviates Rheumatoid Arthritis via Blocking miR296-5p-Mediated Down-Regulation of MMP-15. Int Immunopharmacol (2020) 90:1061-70. doi: 10.1016/j.intimp.2020.107061

250. Yang S, Yin W, Ding Y, Liu F. Lnc RNA ZFAS1 Regulates the Proliferation, Apoptosis, Inflammatory Response and Autophagy of Fibroblast-Like Synoviocytes via miR-2682-5p/ADAMTS9 Axis in Rheumatoid Arthritis. Biosci Rep (2020) 40(8):BSR20201273. doi: 10.1042/bsr20201273

251. Wang W, Guo P, Chen M, Chen D, Cheng Y, He L. FOXM1/LINC00152 Feedback Loop Regulates Proliferation and Apoptosis in Rheumatoid Arthritis Fibroblast-Like Synoviocytes via Wnt/ $\beta$-Catenin Signaling Pathway. Biosci Rep (2020) 40(1):BSR20191900. doi: 10.1042/bsr20191900

252. Wan L, Liu J, Huang C, Zhao L, Jiang H, Liu L, et al. Decreased Long-Chain non-Coding RNA MALAT1 Expression and Increased Hsa-Mir155-3p Expression Involved in Notch Signaling Pathway Regulation in Rheumatoid Arthritis Patients. Xi bao yu fen zi mian yi xue za $z h i=$ Chin J Cell Mol Immunol (2020) 36(6):535-41.

253. Peng T, Ji D, Jiang Y. Long non-Coding RNA GAS5 Suppresses Rheumatoid Arthritis Progression via miR-128-3p/HDAC4 Axis. Mol Cell Biochem (2021) 476(6):2491-501. doi: 10.1007/s11010-021-04098-1

254. Li M, Wang N, Shen Z, Yan J. Long non-Coding RNA Growth ArrestSpecific Transcript 5 Regulates Rheumatoid Arthritis by Targeting Homeodomain-Interacting Protein Kinase 2. Clin Exp Rheumatol (2020) 38(6):1145-54.

255. Su Y, Liu Y, Ma C, Guan C, Ma X, Meng S. Mesenchymal Stem CellOriginated Exosomal IncRNA HAND2-AS1 Impairs Rheumatoid Arthritis Fibroblast-Like Synoviocyte Activation Through miR-143-3p/TNFAIP3/ NF-kb Pathway. J Orthopaed Surg Res (2021) 16(1):116. doi: 10.1186/ s13018-021-02248-1

256. Jiang H, Liu J, Fan C, Wang J, Li W. Lncrnas56464.1 as a ceRNA Promotes the Proliferation of Fibroblast-Like Synoviocytes in Experimental Arthritis via the Wnt Signaling Pathway and Sponges Mir-152-3p. Int J Mol Med (2021) 47(3):1. doi: 10.3892/ijmm.2021.4850 
257. Bi X, Guo XH, Mo BY, Wang ML, Luo XQ, Chen YX, et al. LncRNA PICSAR Promotes Cell Proliferation, Migration and Invasion of Fibroblast-Like Synoviocytes by Sponging miRNA-4701-5p in Rheumatoid Arthritis. EBioMedicine (2019) 50:408-20. doi: 10.1016/j.ebiom.2019.11.024

258. Li G, Liu Y, Meng F, Xia Z, Wu X, Fang Y, et al. LncRNA MEG3 Inhibits Rheumatoid Arthritis Through miR-141 and Inactivation of AKT/mTOR Signalling Pathway. J Cell Mol Med (2019) 23(10):7116-20. doi: 10.1111/ jcmm.14591

259. Yue T, Fan X, Zhang Z, Liu Z, Guo M, Bai F, et al. Downregulation of lncRNA ITSN1-2 Correlates With Decreased Disease Risk and Activity of Rheumatoid Arthritis (RA), and Reduces RA Fibroblast-Like Synoviocytes Proliferation and Inflammation via Inhibiting NOD2/RIP2 Signaling Pathway. Am J Transl Res (2019) 11(8):4650-66.

260. Sun L, Tu J, Liu C, Pan A, Xia X, Chen X. Analysis of lncRNA Expression Profiles by Sequencing Reveals That lnc-AL928768.3 and lnc-AC091493.1 are Novel Biomarkers for Disease Risk and Activity of Rheumatoid Arthritis. Inflammopharmacology (2020) 28(2):437-50. doi: 10.1007/s10787-019-00666-6

261. Hu X, Tang J, Hu X, Bao P, Deng W, Wu J, et al. Silencing of Long NonCoding RNA HOTTIP Reduces Inflammation in Rheumatoid Arthritis by Demethylation of SFRP1. Mol Ther Nucleic Acids (2020) 19:468-81. doi: 10.1016/j.omtn.2019.11.015

262. Yan S, Wang P, Wang J, Yang J, Lu H, Jin C, et al. Long Non-Coding RNA HIX003209 Promotes Inflammation by Sponging miR-6089 via TLR4/NF$\mathrm{\kappa b}$ Signaling Pathway in Rheumatoid Arthritis. Front Immunol (2019) 10:2218. doi: 10.3389/fimmu.2019.02218

263. Yu H, Ding C, Dai S, Sun J, Wang S, Zhang Z. Long Noncoding RNA FER1L4 Regulates Rheumatoid Arthritis via Targeting NLRC5. Clin Exp Rheumatol (2020) 38(4):713-23.

264. Liu C, Guo X, Bai S, Zeng G, Wang H. IncRNA CASC2 Downregulation Participates in Rheumatoid Arthritis, and CASC2 Overexpression Promotes the Apoptosis of Fibroblast-Like Synoviocytes by Downregulating IL-17. Mol Med Rep (2020) 21(5):2131-7. doi: 10.3892/mmr.2020.11018

265. Wang Y, Li G, Guo W, Ji B, Aisikeerbayi A, Boratibai Y, et al. LncRNA PlncRNA-1 Participates in Rheumatoid Arthritis by Regulating Transforming Growth Factor $\beta 1$. Autoimmunity (2020) 53(6):297-302. doi: 10.1080/08916934.2020.1750010

266. Zhi LQ, Zhong Q, Ma JB, Xiao L, Yao SX, Wang X. LncRNA H19 Inhibitor Represses Synovial Cell Proliferation and Apoptosis in Rats With Rheumatoid Arthritis via Notch Signaling Pathway. Eur Rev Med Pharmacol Sci (2020) 24(8):4088-94. doi: 10.26355/eurrev_202004_20985

267. Fu X, Song G, Ni R, Liu H, Xu Z, Zhang D, et al. LncRNA-H19 Silencing Suppresses Synoviocytes Proliferation and Attenuates Collagen-Induced Arthritis Progression by Modulating miR-124a. Rheumatology (Oxford) (2021) 60(1):430-40. doi: 10.1093/rheumatology/keaa395

268. Piao X, Zhou J, Hu J. Role of RP11-83J16.1, a Novel Long non-Coding RNA, in Rheumatoid Arthritis. Am J Transl Res (2020) 12(4):1397-414.

269. Yang J, Li Y, Wang L, Zhang Z, Li Z, Jia Q. LncRNA H19 Aggravates TNF- $\alpha$ Induced Inflammatory Injury via TAK1 Pathway in MH7A Cells. BioFactors (Oxford England) (2020) 46(5):813-20. doi: 10.1002/biof.1659

270. Wang ZQ, Xiu DH, Jiang JL, Liu GF. Long non-Coding RNA XIST Binding to Let-7c-5p Contributes to Rheumatoid Arthritis Through its Effects on Proliferation and Differentiation of Osteoblasts via Regulation of STAT3. J Clin Lab Anal (2020) 34(11):e23496. doi: 10.1002/jcla.23496

271. Liu F, Feng XX, Zhu SL, Lin L, Huang HY, Zhang BY, et al. Long non-Coding RNA SNHG1 Regulates Rheumatoid Synovial Invasion and Proliferation by Interaction With PTBP1. Int Immunopharmacol (2021) 90:107182. doi: 10.1016/j.intimp.2020.107182

272. Liang Y, Li H, Gong X, Ding C. Long Non-Coding RNA THRIL Mediates Cell Growth and Inflammatory Response of Fibroblast-Like Synoviocytes by Activating PI3K/AKT Signals in Rheumatoid Arthritis. Inflammation (2020) 43(3):1044-53. doi: 10.1007/s10753-020-01189-x

273. Zhong S, Ouyang Q, Zhu D, Huang Q, Zhao J, Fan M, et al. Hsa_circ_0088036 Promotes the Proliferation and Migration of Fibroblast-Like Synoviocytes by Sponging miR-140-3p and Upregulating SIRT 1 Expression in Rheumatoid Arthritis. Mol Immunol (2020) 125:1319. doi: 10.1016/j.molimm.2020.07.004

274. Wang L, Zhao Q, Wang N, Ding Y, Kong L, Wang J. Circ_0000396 Inhibits Rheumatoid Arthritis Synovial Fibroblast Growth and Inflammatory
Response via miR-203/HBP1 Axis. J Biol Res (Thessalonike Greece) (2021) 28(1):1. doi: 10.1186/s40709-020-00131-4

275. Zhi L, Liang J, Huang W, Ma J, Qing Z, Wang X. Circ_AFF2 Facilitates Proliferation and Inflammatory Response of Fibroblast-Like Synoviocytes in Rheumatoid Arthritis via the miR-375/TAB2 Axis. Exp Mol Pathol (2021) 119:104617. doi: 10.1016/j.yexmp.2021.104617

276. Yang X, Li J, Wu Y, Ni B, Zhang B. Aberrant Dysregulated Circular RNAs in the Peripheral Blood Mononuclear Cells of Patients With Rheumatoid Arthritis Revealed by RNA Sequencing: Novel Diagnostic Markers for RA. Scand J Clin Lab Invest (2019) 79(8):551-9. doi: 10.1080/00365513. 2019.1674004

277. Luo Q, Liu J, Fu B, Zhang L, Guo Y, Huang Z, et al. Circular RNAs Hsa_circ_0002715 and Hsa_circ_0035197 in Peripheral Blood Are Novel Potential Biomarkers for New-Onset Rheumatoid Arthritis. Dis Markers (2019) 2019:2073139-. doi: 10.1155/2019/2073139

278. Yang J, Cheng M, Gu B, Wang J, Yan S, Xu D. CircRNA_09505 Aggravates Inflammation and Joint Damage in Collagen-Induced Arthritis Mice via miR-6089/AKT1/NF-Kb Axis. Cell Death Dis (2020) 11(10):833-. doi: 10.1038/s41419-020-03038-z

279. Li B, Li N, Zhang L, Li K, Xie Y, Xue M, et al. Hsa_circ_0001859 Regulates ATF2 Expression by Functioning as an MiR-204/211 Sponge in Human Rheumatoid Arthritis. J Immunol Res (2018) 2018:9412387-. doi: 10.1155/ 2018/9412387

280. Luo Q, Zeng L, Zeng L, Rao J, Zhang L, Guo Y, et al. Expression and Clinical Significance of Circular RNAs Hsa_Circ_0000175 and Hsa_Circ_0008410 in Peripheral Blood Mononuclear Cells From Patients With Rheumatoid Arthritis. Int J Mol Med (2020) 45(4):1203-12. doi: 10.3892/ijmm.2020.4498

281. Bartel DP. Metazoan MicroRNAs. Cell (2018) 173(1):20-51. doi: 10.1016/ j.cell.2018.03.006

282. Wang Y, Hou L, Yuan X, Xu N, Zhao S, Yang L, et al. miR-483-3p Promotes Cell Proliferation and Suppresses Apoptosis in Rheumatoid Arthritis Fibroblast-Like Synoviocytes by Targeting IGF-1. Biomed Pharmacother $=$ Biomed Pharmacother (2020) 130:110519. doi: 10.1016/j.biopha.2020.110519

283. Meng H-Y, Chen L-Q, Chen L-H. The Inhibition by Human MSCs-Derived miRNA-124a Overexpression Exosomes in the Proliferation and Migration of Rheumatoid Arthritis-Related Fibroblast-Like Synoviocyte Cell. BMC Musculoskeletal Disord (2020) 21(1):150-. doi: 10.1186/s12891-020-3159-y

284. Zhao W, Li D, Su Y, Zhao H, Pang W, Sun Y, et al. MicroRNA-147 Negatively Regulates Expression of Toll-Like Receptor-7 in Rat Macrophages and Attenuates Pristane Induced Rheumatoid Arthritis in Rats. Am J Transl Res (2019) 11(4):2219-31.

285. Yuan M, Wang S, Yu L, Qu B, Xu L, Liu L, et al. Long Noncoding RNA Profiling Revealed Differentially Expressed lncRNAs Associated With Disease Activity in PBMCs From Patients With Rheumatoid Arthritis. PloS One (2017) 12(11):e0186795. doi: 10.1371/journal.pone.0186795

286. Zhang Y, Xu YZ, Sun N, Liu JH, Chen FF, Guan XL, et al. Long Noncoding RNA Expression Profile in Fibroblast-Like Synoviocytes From Patients With Rheumatoid Arthritis. Arthritis Res Ther (2016) 18(1):227. doi: 10.1186/ s13075-016-1129-4

287. Xu D, Jiang Y, Yang L, Hou X, Wang J, Gu W, et al. Long Noncoding RNAs Expression Profile and Functional Networks in Rheumatoid Arthritis. Oncotarget (2017) 8(56):95280-92. doi: 10.18632/oncotarget.20036

288. Liu YR, Yang L, Xu QQ, Lu XY, Ma TT, Huang C, et al. Long Noncoding RNA MEG3 Regulates Rheumatoid Arthritis by Targeting NLRC5. J Cell Physiol (2019) 234(8):14270-84. doi: 10.1002/jcp.28126

289. Yang Z, Lin SD, Zhan F, Liu Y, Zhan YW. LncRNA GAS5 Alleviates Rheumatoid Arthritis Through Regulating miR-222-3p/Sirt1 Signalling Axis. Autoimmunity (2020) 54(1):13-22. doi: 10.1080/08916934.2020.1846183

290. Xia X, Tang X, Wang S. Roles of CircRNAs in Autoimmune Diseases. Front Immunol (2019) 10:639. doi: 10.3389/fimmu.2019.00639

291. Wen J, Liu J, Zhang P, Jiang H, Xin L, Wan L, et al. RNA-Seq Reveals the Circular RNA and miRNA Expression Profile of Peripheral Blood Mononuclear Cells in Patients With Rheumatoid Arthritis. Biosci Rep (2020) 40(4):BSR20193160. doi: 10.1042/BSR20193160

292. Li G, Tan W, Fang Y, Wu X, Zhou W, Zhang C, et al. Circfads2 Protects LPSTreated Chondrocytes From Apoptosis Acting as an Interceptor of miR-498/ mTOR Cross-Talking. Aging (2019) 11(10):3348-61. doi: 10.18632/ aging. 101986 
293. Nakano K, Whitaker JW, Boyle DL, Wang W, Firestein GS. DNA Methylome Signature in Rheumatoid Arthritis. Ann Rheum Dis (2013) 72 (1):110-7. doi: 10.1136/annrheumdis-2012-201526

294. Karouzakis E, Raza K, Kolling C, Buckley CD, Gay S, Filer A, et al. Analysis of Early Changes in DNA Methylation in Synovial Fibroblasts of RA Patients Before Diagnosis. Sci Rep (2018) 8(1):7370-. doi: 10.1038/s41598-018-24240-2

295. Pitaksalee R, Burska AN, Ajaib S, Rogers J, Parmar R, Mydlova K, et al. Differential CpG DNA Methylation in Peripheral Naïve CD4(+) T-Cells in Early Rheumatoid Arthritis Patients. Clin Epigenet (2020) 12(1):54-. doi: 10.1186/s13148-020-00837-1

296. Gilbert WV, Bell TA, Schaening C. Messenger RNA Modifications: Form, Distribution, and Function. Sci (New York NY) (2016) 352(6292):1408-12. doi: 10.1126/science.aad8711

297. Huang Y, Yan J, Li Q, Li J, Gong S, Zhou H, et al. Meclofenamic Acid Selectively Inhibits FTO Demethylation of M6a Over ALKBH5. Nucleic Acids Res (2015) 43(1):373-84. doi: 10.1093/nar/gku1276

298. Jiang H, Cao K, Fan C, Cui X, Ma Y, Liu J. Transcriptome-Wide HighThroughput M6a Sequencing of Differential M6a Methylation Patterns in the Human Rheumatoid Arthritis Fibroblast-Like Synoviocytes Cell Line MH7A. J Inflammation Res (2021) 14:575-86. doi: 10.2147/jir.S296006

299. Tessarz P, Kouzarides T. Histone Core Modifications Regulating Nucleosome Structure and Dynamics. Nat Rev Mol Cell Biol (2014) 15 (11):703-8. doi: 10.1038/nrm3890

300. Wang F, Chen FF, Gao WB, Wang HY, Zhao NW, Xu M, et al. Identification of Citrullinated Peptides in the Synovial Fluid of Patients With Rheumatoid Arthritis Using LC-MALDI-TOF/TOF. Clin Rheumatol (2016) 35(9):218594. doi: 10.1007/s10067-016-3247-4

301. Kawabata T, Nishida K, Takasugi K, Ogawa H, Sada K, Kadota Y, et al. Increased Activity and Expression of Histone Deacetylase 1 in Relation to Tumor Necrosis Factor-Alpha in Synovial Tissue of Rheumatoid Arthritis. Arthritis Res Ther (2010) 12(4):R133. doi: 10.1186/ar3071

302. Angiolilli C, Grabiec AM, Ferguson BS, Ospelt C, Malvar Fernandez B, van Es IE, et al. Inflammatory Cytokines Epigenetically Regulate Rheumatoid Arthritis Fibroblast-Like Synoviocyte Activation by Suppressing HDAC5 Expression. Ann Rheum Dis (2016) 75(2):430-8. doi: 10.1136/annrheumdis2014-205635
303. Hao L, Wan Y, Xiao J, Tang Q, Deng H, Chen L. A Study of Sirt1 Regulation and the Effect of Resveratrol on Synoviocyte Invasion and Associated Joint Destruction in Rheumatoid Arthritis. Mol Med Rep (2017) 16(4):5099-106. doi: 10.3892/mmr.2017.7299

304. Woo SJ, Lee SM, Lim HS, Hah YS, Jung ID, Park YM, et al. Myeloid Deletion of SIRT1 Suppresses Collagen-Induced Arthritis in Mice by Modulating Dendritic Cell Maturation. Exp Mol Med (2016) 48(3):e221. doi: 10.1038/ emm.2015.124

305. Angiolilli C, Kabala PA, Grabiec AM, Van Baarsen IM, Ferguson BS, García $S$, et al. Histone Deacetylase 3 Regulates the Inflammatory Gene Expression Programme of Rheumatoid Arthritis Fibroblast-Like Synoviocytes. Ann Rheum Dis (2017) 76(1):277-85. doi: 10.1136/annrheumdis-2015-209064

306. Klein K, Kabala PA, Grabiec AM, Gay RE, Kolling C, Lin LL, et al. The Bromodomain Protein Inhibitor I-BET151 Suppresses Expression of Inflammatory Genes and Matrix Degrading Enzymes in Rheumatoid Arthritis Synovial Fibroblasts. Ann Rheum Dis (2016) 75(2):422-9. doi: 10.1136/annrheumdis-2014-205809

307. Cribbs AP, Terlecki-Zaniewicz S, Philpott M, Baardman J, Ahern D, Lindow M, et al. Histone H3K27me3 Demethylases Regulate Human Th17 Cell Development and Effector Functions by Impacting on Metabolism. Proc Natl Acad Sci USA (2020) 117(11):6056-66. doi: 10.1073/pnas.1919893117

308. Trenkmann M, Brock M, Gay RE, Kolling C, Speich R, Michel BA, et al. Expression and Function of EZH2 in Synovial Fibroblasts: Epigenetic Repression of the Wnt Inhibitor SFRP1 in Rheumatoid Arthritis. Ann Rheum Dis (2011) 70(8):1482-8. doi: 10.1136/ard.2010.143040

Conflict of Interest: The authors declare that the research was conducted in the absence of any commercial or financial relationships that could be construed as a potential conflict of interest.

Copyright (c) 2021 Huang, Fu, Chen, Li, Huang and Liang. This is an open-access article distributed under the terms of the Creative Commons Attribution License (CC BY). The use, distribution or reproduction in other forums is permitted, provided the original author(s) and the copyright owner(s) are credited and that the original publication in this journal is cited, in accordance with accepted academic practice. No use, distribution or reproduction is permitted which does not comply with these terms. 